TITLE:

\title{
Flutter and its application-Flutter mode and ship navigation
}

$\operatorname{AUTHOR}(S)$ :

Matsumoto, Masaru

\section{CITATION:}

Matsumoto, Masaru. Flutter and its application-Flutter mode and ship navigation. Journal of Wind Engineering and Industrial Aerodynamics 2013, 122: 10-20

ISSUE DATE:

2013-11

URL:

http://hdl.handle.net/2433/179477

\section{RIGHT:}

(c) 2013 Elsevier Ltd.; この論文は出版社版でありません。引用の際には 出版社版をご確認ご利用ください。; This is not the published version. Please cite only the published version. 


\title{
Flutter and Its Application - Flutter mode and Ship Navigation
}

\author{
Masaru Matsumoto,* \\ a * professor emeritus at Kyoto University, Japan \\ E-mail:matsu@brdgeng.gee.kyoto-u.ac.jp, Tel: +81-774-32-5931
}

Keywords: Drastic change of vibrational mode of Tacoma Narrows Bridge, coupled flutter, 2DOF SBS analysis, 3DOF SBS analysis, multi-mode SBS flutter analysis, flutter branch, flutter mode, propulsion force by H-90 flutter mode, Ship navigation test by flapping plate

\begin{abstract}
.
Another explanation of drastic change of vibrational mode from $5^{\text {th }}$ symmetrical heaving mode to $1^{\text {st }}$ asymmetrical torsional mode is shown, basing on aerodynamic interaction between heaving vortexinduced vibration and torsional flutter. Some fundamentals of coupled flutter of thin plates and plate like structures are shown. 3DOF(and 3 modes) flutter analysis and multi-modes(3DOF) flutter analysis are compared with the one obtained by 2DOF (2modes) flutter analysis. In order to stabilize flutter instability of long spanned suspension bridge, reduction of $A 2 *$ eq can be realized by suitably combining girders with $[A 1 *>0, A 2 *<0]$ and $\left[A 1^{*}<0, A 2 *>0\right]$ is studied. Multi-modes and 3DOF flutter analysis is needed to precisely verify the flutter instability of long span bridges as a lesson from full scale model test and flutter analysis of Akashi Kaikyo Bridge. Flutter branch and flutter mode are discussed. In particular in flutter modes of thin plate consisted in two major modes, TO and H-90. It is shown that simple assumption of flutter onset at $f \eta 0=f \varphi$ and quasi-steady of $F(k)=1$ and $G(k)=0$ ( $F$ and $G$ :real part and imaginary part of Theodorsen function ), significantly similar formula with Selberg formula can be driven. As an application of flutter to get propulsion force, thin airfoil term and jet disgorging part are individually discussed. The results of ship navigation test by use of flapping plate controlled in H-90mode are introduced.
\end{abstract}

\section{INTRODUCTION}

Author has studied on flutter instability of plate like structures, including bluff bodies. In particular, it has been verified that Step-by step (SBS) flutter analysis, proposed by author, inform various useful information on coupled flutter mechanism.. It has been reported by author the role of fundamental modes of coupled flutter of plate like structures on flutter instability (Matsumoto et al.[1]). Major modes are T0 mode and H-90 mode. T0 mode as a torsional branch is fundamentally torsional vibration around the leading edge of section and the phase difference between heaving and torsional vibration around midchord point is zero degree. On the other hand, H-90 mode as heaving branch is dominative heaving vibration in coupling heaving and torsional motion with phase difference of -90 degree. Where phase difference is defined as the phase lag of the maximum torsional displacement, which is the maximum nose-up state to the flow, from the heaving one, which is the lowest state. Coupled flutter of plate-like structures onset with T0 dominative mode and then flutter mode changes from T0 dominative mode to H-90 mode, with increase of velocity after onset of flutter. As a matter of fact, the full scale elastic model of Akashi Kaikyo Bridge showed T0 dominative mode at the onset of coupled flutter (Kusuhara and Matsumoto[2]). This mode changing characteristics with wind velocity have been verified in heaving/torsional 2DOF free vibration test, of the flat rectangular cylinder with the side ration of $B / D=20$ (Matsumoto et al.[1]). Furthermore, flutter power generation system has been studied basing on flutter mode( Isogai and et al.[3], Abiru and et al.[4], and Matsumoto et al. [5]) Where it has been verified that H-90 mode plays significant 
important role to get more efficiently power from wind/fluid. Aoki[6] has recently studied on the wing stroke system for wind power generation, which is similar with flapping wing of bird and an application of modified H-90 mode. It has been understood that fishes might sophisticatedly use the unsteady fluiddynamic force for high speed swimming in controlled combination of sway (heaving) and pitching (torsional) motion of their bodies and tail fins. On optimization of dolphin swimming is studied by Isogai and et al.[7]. For example, it has been pointed out that sword fish and dolphin can swim up to $80 \mathrm{Km} / \mathrm{h}$ and 60 $\mathrm{Km} / \mathrm{s}$, respectively. Learning fish swimming, ship navigation system with flapping plate has been studied (Tanaka and Nagai[8] and Terada et al.[9]). Furthermore, the propulsion forces generated by rigid and flexible flapping plates has been studied by Barannyk et al.[10]. It has been pointed out in former studies on ship navigation with flapping plate that the effective propulsion force in this system can be achieved by suitable combination of sway and pitching motion, those are phase difference of -90 degree, corresponding H-90 flutter mode, and amplitude ratio between sway and pitching motion. Recently ones of authors pointed out the similarity in naturally generated coupled flutter, flutter power generation and ship navigation with flapping plate, from the point of essential role of flutter mode, H-90. (Matsumoto and Ishizaki[11]). However, details of the generation mechanism of propulsion force produced by $\mathrm{H}-90$ flutter mode, including high speed swimming of sword fish and dolphin, are not verified. If this issue would be satisfactorily resolved, significant improvement of power generation system from fluid and more effective navigation system of ship and submarine would be expected from the point of getting huge energy by small energy by use of fluid-structure interaction. The authors challenge to study on this issue, basing on the study of fundamentals on flutter mechanism of long span bridge and thin plate. In this paper, the authors describe the significant role of $\mathrm{H}-90$ flutter mode on generation of propulsion force and simple modeling of propulsion force, through basic water flume test for ship navigation with flapping plates.

\section{Another explanation of sudden change of vibration mode of Tacoma Narrows Bridge in 1940}

Original Tacoma Narrows Bridge had plate-girder with $\mathrm{H}$-shape section with $\mathrm{B} / \mathrm{D}=5$. This bridge showed catastrophic torsional oscillation by $1^{\text {st }}$ asymmetrical mode, after showing $5^{\text {th }}$ heaving symmetrical mode under wind velocity less than $20 \mathrm{~m} / \mathrm{s}$. Its frequency ratio, $\mathrm{f} \varphi \mathrm{o} / \mathrm{f} \eta 0$, corresponding these modes, is 2.5 . As far as sudden change of vibrational mode from $5^{\text {th }}$ symmetrical heaving mode to ist asymmetrical tororsional mode, it has been reported that it had been caused by the being broken of center diagonal stay cable, which had been instaaled for prevension of torsional displacement of main bridge girder.[12] Taking into account of serious damage of main cable cable wires near at center diagonal stay cable band on main cable, it clearly describes that torsional vibration had already started before sudden change of vibrational mode of bridge girder. Furthermore, At bridge site, wind velocity at center part of "Narrows"might be in general larger than the one of near land, it means of larger wind velocity blowed at center span than the one of side span. If looking carefully the $35 \mathrm{~mm}$ motion film taken by Farqursen's group at the site, Center span vibrated in $1^{\text {st }}$ asymmetrical torsional mode with $0.23 \mathrm{~Hz}$ but side span indicated $5^{\text {th }}$ symmetrical heaving mode with $0.6 \mathrm{~Hz}$. This events implied that Tacoma bridge girder might drastically change at this specified wind velocity. Thus free-vibration wind tunnel tests, heaving $1 \mathrm{DOF}$ test, torsional $1 \mathrm{DOF}$ test and heaving/torsional 2DOF test, have been carried out to verify the aerodynamic interference between heaving and torsional motion by use of section model. Heaving and torsional response in 2DOF is shown in Fig.1 . At 16-17m/s, heaving vibration related to vortex induced vibration suddenly changed to torsional vibration related to torsional flutter under structural torsional damping of around $\delta=0.08$. In another expression, at this particular wind velocity there Tacoma bridge girder would posess significant aerodynamic interaction between heavin vortex-induded vibration and torsional flutter. The catastrophic wind velocity at site has been reported as $18-19 \mathrm{~m} / \mathrm{s}$. On this matter, bridge skewly cross narrows approximately 25 degree, it means effective wind velocity must be $16-17 \mathrm{~m} / \mathrm{s}$. (On more details, see literature [13]) 


\section{Coupled Flutter}

\subsection{Heaving/torsional Coupled flutter( 2modes 2DOF flutter)}

Heaving and torsional differential equatios can be expressed by 8 aerodynamic derivatives as follows[14]: (1) $\mathrm{m}\left(\mathrm{d}^{2} \eta / \mathrm{dt}^{2}\right)+\mathrm{C}_{\eta}(\mathrm{d} \eta / \mathrm{dt})+\mathrm{k}_{\eta} \eta=(1 / 2) \rho(2 \mathrm{~b}) \mathrm{V}^{2}\left(\mathrm{kH}_{1} *(\mathrm{~d} \eta / \mathrm{dt}) / \mathrm{V}+\mathrm{kH}_{2} * \mathrm{~b}(\mathrm{~d} \varphi / \mathrm{dt}) / \mathrm{V}+\mathrm{k}^{2} \mathrm{H}_{3} *{ }^{*}+\mathrm{k}^{2} \mathrm{H}_{4} *(\eta / \mathrm{b})\right)$

$\mathrm{I}\left(\mathrm{d}^{2} \varphi / \mathrm{dt}^{2}\right)+\mathrm{C}_{\varphi}(\mathrm{d} \varphi / \mathrm{dt})+\mathrm{k}_{\varphi} \varphi=(1 / 2) \rho\left(2 \mathrm{~b}^{2}\right) \mathrm{V}^{2}\left(\mathrm{kA}_{1} *(\mathrm{~d} \eta / \mathrm{dt}) / \mathrm{V}+\mathrm{kA}_{2} * \mathrm{~b}(\mathrm{~d} \varphi / \mathrm{dt}) / \mathrm{V}+\mathrm{k}^{2} \mathrm{~A}_{3} * \varphi+\mathrm{k}^{2} \mathrm{~A}_{4} *(\eta / \mathrm{b})\right)$ (2)

where, $\mathrm{m}, \mathrm{I}$ : mass and mass inertia per unit length, $\mathrm{C} \eta, \mathrm{C} \varphi$ : heaving and torsional damping coefficient, $\mathrm{k} \eta$, $\mathrm{k} \varphi$ : heaving and torsional stiffness, $\rho$ :airdensity, b:half chord length, V:on-coming velocity, $\mathrm{k}$ : reduced velocity $(=\mathrm{b} \omega / \mathrm{V}, \omega$ :corcular frequency $), \mathrm{H}_{\mathrm{i}}{ }^{*}$ and $\mathrm{A}_{\mathrm{i}}{ }^{*}$ : flutter derivatives $(\mathrm{i}=1-4)$

The 8 aerodynamic derivatived of thin plate can be shown by use of Theodorsen function.

$$
\begin{array}{ll}
\mathrm{H}_{1} *(\mathrm{k})=-(2 \pi / \mathrm{k}) \mathrm{F}(\mathrm{k}), & \mathrm{A}_{1} *(\mathrm{k})=(\pi / \mathrm{k}) \mathrm{F}(\mathrm{k}) \\
\mathrm{H}_{2} *(\mathrm{k})=-(2 \pi / \mathrm{k})(-(1 / 2)+\mathrm{F}(\mathrm{k}) / 2-\mathrm{G}(\mathrm{k}) / \mathrm{k}), & \mathrm{A}_{2} *(\mathrm{k})=(\pi / \mathrm{k})(-(1 / 2)+\mathrm{F}(\mathrm{k}) / 2-\mathrm{G}(\mathrm{k}) / \mathrm{k}) \\
\mathrm{H}_{3} *(\mathrm{k})=-(2 \pi / \mathrm{k})(\mathrm{F}(\mathrm{k}) / \mathrm{k}+\mathrm{G}(\mathrm{k}) / 2) & \mathrm{A}_{3} *(\mathrm{k})=(\pi / \mathrm{k})(\mathrm{F}(\mathrm{k}) / \mathrm{k}+\mathrm{G}(\mathrm{k}) / 2) \\
\mathrm{H}_{4} *(\mathrm{k})=-(2 \pi / \mathrm{k}) \mathrm{G}(\mathrm{k}) & \mathrm{A}_{4} *(\mathrm{k})=(\pi / \mathrm{k}) \mathrm{G}(\mathrm{k})
\end{array}
$$

where $\mathrm{C}(\mathrm{k})=\mathrm{F}(\mathrm{k})-\mathrm{iG}(\mathrm{k})$

where, $\mathrm{C}(\mathrm{k})$ : Theodorsen function

\subsection{Relation of aerodynamic derivatives}

Basing on the similarity of unsteady pressure properties, amplitude and phase characteristics, of rectangular cylinders with various side ratios under heaving forced vibration and torsional one, if relative piching angle is identical, that is $\mathrm{d} \eta / \mathrm{dt} / \mathrm{V}$ and $\varphi$, as shown in Fig.2.

These 8 aerodynamic derivatives can be obtained from integration of unsteady pressure , those are $\mathrm{Cp}$ and $\Psi($ Matsumoto[15]).

Then, the following relations acan be obtained:

$$
\begin{aligned}
& \mathrm{H}_{3} *=\mathrm{H}_{1} * / \mathrm{k}, \mathrm{H}_{2} *=-\mathrm{H}_{4} * / \mathrm{k} \\
& \mathrm{A}_{3} *=\mathrm{A}_{1} * / \mathrm{k}, \quad \mathrm{A}_{2} *=-\mathrm{A}_{4} * / \mathrm{k}
\end{aligned}
$$

These relations between aerodynamic derivatives expressed in equation(4) are confirmed for rectangular cylinders with various side ratios. Furthermore, taking into account of relation beween theodorsen function $(\mathrm{C}(\mathrm{k}))$, that is complex function associated to reduced frequency $\mathrm{k}$, and Wagner function $\left(\psi_{\mathrm{w}}(\tau)\right)$, that is real function associated to reduced time $\tau$. Noting that Wagner function is obtained by inverse Laplace transformation of Theodorsen function, another relation in aerodynamic derivatives of $\left(\mathrm{H}_{1} *\right.$ and $\left.\mathrm{H}_{4} *\right)$ and $\left(\mathrm{A}_{2} *\right.$ and $\mathrm{A}_{3} *$ ). Finally only two aerodynamic derivatives are independent in 8 aerodynamic derivatives. Since in particular, $\mathrm{A}_{2} *$ and $\mathrm{H}_{1} *$ are easily and precisely obtained by heaving and torsional 1DOFfree vibration test, respectively. This relation in aerodynamic derivatives can be said to be practically convenient to evaluate other 6 derivatives. 
Fig. 3 shows the $\mathrm{V}-\delta$ diagram obtained by measured 8 aerodynamic derivatives and only two derivatives, $\mathrm{H}_{1} *$ and $\mathrm{A}_{2} *$, as flutter property of rectangular cylinders with $\mathrm{B} / \mathrm{D}=5$ and 20 (B:alongwind length, D:crosswind length). Sufficient agreement between them(Solid line and dotted line) can be observed as shown in Fig.3.

\subsection{Flutter Analysis}

Complex Eigen value analysis( CEV analysis) has been widely used for verification of flutter properties, those are damping, frequency, amplitude ratio and phase properties. On the other hand, author proposed another method, named as "step-by-step" analysis (SBS analysis). The flutter properties obtained from these two different methods are completely identical, exceptionally flutter branch. In CEV analysis flutter branch has not clearly been classified, on the other hand, in SBS analysis, flutter branch can be clearly defined.

\subsection{SBS analysis}

What is SBS analysis is simply explained as catching ball analysis in terms of damping and frequency between heaving system and torsional system indicated in equation(1) through free-vibration and forcedvibration effects illustrated in Fig.4(Heaving branch) and Fig.5 (Torsional Branch ) (Matsumoto et al.[1]).

For torsional branch case, at first damping $\delta_{1}$ and frequency $\mathrm{f}_{1}$ are assumed (step1), then heaving equation is affected by through coupling aerodynamic derivatives $\mathrm{H}_{2} *$ and $\mathrm{H}_{3} *$ as forced-vibration(step2), then amplitude ratio and phase are obtained. At next torsional system is affected through coupled aerodynamic derivatives $\mathrm{A}_{1}{ }^{*}$ and $\mathrm{A}_{4} *$ as free-vibration effect,.(step3). From step 3, damping $\delta_{2}$ and frequency $\mathrm{f}_{2}$ are obtained. This procedure is repeated till $\left(\delta_{1}, \mathrm{f}_{1}\right)=\left(\delta_{2}, \mathrm{f}_{2}\right)$. Thus, flutter characteristics, those are damping $\delta$, frequency fF, phase difference $\psi$ and amplitude ratio $\eta_{0} / \varphi_{0}$ are analyzed. Fig. 6 and Fig.7 shows them of thin plate with certain dynamics. In this figure, results obtained by CEV analysis are also indicated. It should be noted that Results obtained by CEV and SBS analysis completely coincide, exceptionally branch switch.

\subsection{Flutter Branch}

Heaving branch(HB) and torsional branch(TB) during flutter instability can be defined as heaving mode dominated branch and torsional mode dominated branch, which can be confirmed by flutter vibration mode of rectangular cylinder with $\mathrm{B} / \mathrm{D}=20$.

Or HB can be defined as flutter controlled by heaving system in equation(1) and TB can be controlled by torsional system in equation(1).

In Fig.6 and Fig.7, it should be noted that flutter branches suddenly change neat flutter onset velocity. On these drastic change of flutter branch would occur near at phase angle(delay of torsional maximum from heaving maximum) of $\psi=-45$ degree and amplitude ratio of minimum $\left(\eta_{0} / \varphi_{0}\right)$ for all cases, and it should be related to "Hop Bifurcation" but its physical explanation should be a future subject.

\subsection{Role of aerodynamic derivatives}

The contribution of each aerodynamic derivatives on the damping can be verified by use of SBS analysis. The total damping $\delta$ of TB and $\mathrm{HB}$ of thin plate can be mainly characterized by $\mathrm{A}_{2} * \mathrm{~A}_{1} *$ and $\mathrm{H}_{3} *$ for TB, 
and $\mathrm{H}_{1} * \mathrm{~A}_{1} *$ and $\mathrm{H}_{3} *$ for $\mathrm{HB}$, respectively, as shown in Fig.8. It means that control of $\mathrm{A}_{1} *$ and $\mathrm{H}_{3} *$ is definitely important for coupled flutter stabilization .

\subsection{Flutter Modes}

Amplitude ratio, $\eta_{0} / \varphi_{0}$, and phase, $\psi$, properties in four flutter properties (see Fig.6 and Fig.7) can characterize flutter coupling modes. In coupled flutter, 6 fundamental modes can be defined as follows:

1. $\mathrm{H}$ mode: This is pure $1 \mathrm{DOF}$ heaving mode without torsional displacement, in another expression, is pure torsional mode around rotational axis fixed at the point with infinite distance from mid-chord point of plate.

2. T mode: This is pure rotational mode around rotational axis fixed at mid-chord point of plate, without heaving displacement at this point.

3. T0 mode: This is pure rotational mode around leading edge. At heaving motion (the lowest is maximum) at mid-chord point has no phase difference against torsional motion(windward nose-up positive) at this point.

4. T180 mode: This is pure rotational mode around trailing edge. In this mode, torsional maximum delays from heaving maximum by -180 degree.

5. H90 mode: In this mode, the heaving maximum delays from the torsional maximum by 90 degree. This mode appears from quasi-steady point if $\mathrm{dC}_{\mathrm{L}} / \mathrm{d} \alpha<0$.

6. H-90 mode: In this mode, the heaving maximum delays from the torsional maximum by -90 degree, it means the heaving maximum proceeds ahead to the torsional maximum by 90 degree. This mode appears from quasi-steady point if $\mathrm{dC} / \mathrm{d} \alpha>0$.

$\mathrm{H}$ mode and $\mathrm{T}$ mode described above are not coupling modes, in consequence four coupling modes, $\mathrm{T} 0$, T180, H90 and H-90, are illustrated in Fig.9

At velocity range near $\mathrm{Vcr}$, flutter branch would be defined from phase difference, $\Psi$, as following procedure. Taking into account of flutter modes, $\mathrm{H}$ mode, T mode, T0 mode, T180 mode, H90 mode and H-90 mode, their torsional motion, $\varphi(t)$, and heaving motion, $\eta(t)$ are expressed respectively as follow:

$H$ mode: $\eta(t)=\eta_{0} \sin \omega t$

$$
\varphi(t)=0 \quad(5.1)
$$

T mode: $\varphi(t)=\varphi_{0} \sin \omega t$

$$
\eta(\mathrm{t})=0 \quad(5.2)
$$

T0 mode: $\varphi(t)=\varphi_{0} \sin \omega t$

$$
\eta(\mathrm{t})=\eta_{0} \sin \omega \mathrm{t}
$$

T180 mode: $\varphi(t)=\varphi_{0} \sin \omega t$

$$
\eta(t)=-\eta_{0} \sin \omega t \quad(5.4)
$$

H90 mode: $\varphi(t)=\varphi_{0} \sin \omega t$

$$
\eta(t)=-\eta_{0} \cos \omega t
$$

H-90 mode: $\varphi(t)=\varphi_{0} \sin \omega t$

$$
\eta(t)=\eta_{0} \cos \omega t
$$

When phase difference between torsion and heaving motion is $\Psi$, coupling of heaving and torsional motions can be expressed as follow depending on $\Psi$ which varies between $-90^{\circ}$ and $180^{\circ}$ in flutter property obtained by flutter analysis :

$180^{\circ}>\Psi>90^{\circ}: \cos \Psi<0$ and $\sin \Psi>0, \quad(5.7)$ 
$90^{\circ}>\Psi>0^{\circ}: \cos \Psi>0$ and $\sin \Psi>0$,

$0>\Psi>-90^{\circ}: \cos \Psi>0$ and $\sin \Psi<0$.

Then,

$$
\begin{aligned}
& \varphi(t)=\varphi_{0} \sin \omega t \\
& \eta(t)=\eta_{0} \sin (\omega t-\Psi) \\
& =\eta_{0} \sin \omega t \cos \Psi-\eta_{0} \cos \omega t \sin \Psi
\end{aligned}
$$

For all terms on right hand of the upper equation, coupling motions can be resolved as follows:

$$
\begin{gathered}
180^{\circ}>\Psi>90^{\circ}: \varphi(\mathrm{t})=\varphi_{0} \sin \omega \mathrm{t} \\
\eta(\mathrm{t})=-\mathrm{T} 180 \cos \Psi-\mathrm{H} 90 \sin \Psi \\
0^{\circ}>\Psi>-90^{\circ}: \varphi(\mathrm{t})=\varphi_{0} \sin \omega \mathrm{t} \\
\eta(\mathrm{t})=-\mathrm{T} 0 \cos \Psi-\mathrm{H}-90 \sin \Psi \\
90^{\circ}>\Psi>0^{\circ}: \varphi(\mathrm{t})=\varphi_{0} \sin \omega \mathrm{t} \\
\eta(\mathrm{t})=\mathrm{T} 0 \cos \Psi+\mathrm{H} 90 \sin \Psi
\end{gathered}
$$

At near Vcr as shown in Fig.6 and Fig.7, flutter branch, HB or TB, which consists of T0 mode and H-90 mode for amplitude ratio- velocity diagram, can be classified by their magnitude of coefficients, those are $\sin \Psi$ and $\cos \Psi$. If $\Psi=-45^{\circ}$, the contribution to flutter of TB and $\mathrm{HB}$ are identical. If $\Psi<-45^{\circ}$, HB plays more significantly for flutter onset than TB, and contrary if $\Psi>-45^{\circ}$, TB does than HB. Flutter branch when flutter occurs changes not only with different aerodynamic derivatives caused by change of geometrical shape of structures or with angle of attack of wind, but also with structural dynamics.

It should be noted that flutter branch at flutter onset changes by structural dynamics. In full scale model test of Akashi Kaikyo Bridge, Flutter onset was in T0 mode, on the other hand, in full scale elastic model test of Sutong Bridge in China, which is the second longest cable stayed bridge in the world, flutter begins in T0 mode at final construction stage under the horizontal wind, but it begins in H-90 mode under up-ward wind with the angle of attack of $3^{\circ}$ at completed stage (Xu You[16]). In this case, different aerodynamic derivatives change flutter branch at flutter onset.

\subsection{DOF Coupled flutter (3 modes)}

Lift (L), Pitching moment (M) and Drag(D) associated with 3DOF flutter with each three modes can be expressed by use of 16aerodynamic derivatives as follows:

$\mathrm{L}=(1 / 2) \rho \mathrm{V}^{2}(2 \mathrm{~b})\left(\mathrm{kH}_{1} *((\mathrm{~d} \eta / \mathrm{dt}) / \mathrm{V})+\mathrm{kH}_{2} *(\mathrm{~b}(\mathrm{~d} \varphi / \mathrm{dt}) / \mathrm{V})+\mathrm{k}^{2} \mathrm{H}_{3} * \varphi+\mathrm{k}^{2} \mathrm{H}_{4} *(\eta / \mathrm{b})+\mathrm{kH}_{5} *(\mathrm{~d} \xi / \mathrm{dt}) / \mathrm{V}+\mathrm{k}^{2} \mathrm{H}_{6} *(\xi / \mathrm{b})\right)$

$\mathrm{M}=(1 / 2) \rho \mathrm{V}^{2}\left(2 \mathrm{~b}^{2}\right)\left(\mathrm{kA}_{1} *((\mathrm{~d} \eta / \mathrm{dt}) / \mathrm{V})+\mathrm{kA}_{2} *(\mathrm{~b}(\mathrm{~d} \varphi / \mathrm{dt}) / \mathrm{V})+\mathrm{k}^{2} \mathrm{~A}_{3} * \varphi+\mathrm{k}^{2} \mathrm{~A}_{4} *(\eta / \mathrm{b})+\mathrm{kA}_{5} *(\mathrm{~d} \xi / \mathrm{dt}) / \mathrm{V}+\mathrm{k}^{2} \mathrm{~A}_{6} *(\xi / \mathrm{b})\right)$

$\mathrm{D}=(1 / 2) \rho V^{2}(2 \mathrm{~b})\left(\mathrm{kP}_{1} *((\mathrm{~d} \xi / \mathrm{dt}) / \mathrm{V})+\mathrm{kP}_{2} *(\mathrm{~b}(\mathrm{~d} \varphi / \mathrm{dt}) / \mathrm{V})+\mathrm{k}^{2} \mathrm{P}_{3} * \varphi+\mathrm{k}^{2} \mathrm{P}_{4} *(\xi / \mathrm{b})+\mathrm{kP}_{5} *(\mathrm{~d} \eta / \mathrm{dt}) / \mathrm{V}+\mathrm{k}^{2} \mathrm{H}_{6} *(\eta / \mathrm{b})\right)$

(6)

where L, M, D: unsteady lift, pitching moment and drag, respectively, $\xi$ : horizontal (windward) displacement, $\mathrm{H}_{\mathrm{i}}{ }^{*}, \mathrm{~A}_{\mathrm{i}}{ }^{*}, \mathrm{P}_{\mathrm{i}}{ }^{*}$ :aerodynamic derivatives (i=1-6) 
Similarly with SBS analysis of the case of 2DOF(and 2modes) flutter, 3DOF (and 3 modes) flutter can be analyzed by SBS analysis[17].

In the case of the flutter properties, those are damping $\delta$ and frequency $\mathrm{f}_{\mathrm{F}}$, of Akashi Kaikyo Bridge obtained by 2DOF(and 2modes) SBS flutter analysis, 3DOF (and 3 modes) SBS flutter analysis and 3DOF (and 3 modes) CEV flutter analysis are compared both damping and frequency obtained by these three analysis show almost same results, hence it is implied that 3DOF effect, in another words windward effect or drag effect, might be negligible on flutter characteristics. (Matsumoto et al.[17])

\subsection{Multi-modes flutter analysis}

Multi-modes flutter SBS analysis can be carried out similarly with 2DOFand 2 mode SBS analysis, and 3DOF and 3mode SBS analysis[17]. Flutter properties, those are damping $\delta$ and frequency $\mathrm{f}_{\mathrm{F}}$, of Akashi Kaikyo Bridge obtained by multi-modes SBS analysis where 27 modes are taken into account in comparison with the results obtained multi-modes CEV analysis (Matsumoto and Matsumiya[17]). Both results show the same, but in SBS results all flutter branches can be identified. Furthermore, mode contribution on flutter instability of fundamental mode (leading mode) can be clarified.

For example, on flutter critical velocity, $\mathrm{Vcr}, 84 \mathrm{~m} / \mathrm{s}$ obtained for $2 \mathrm{DOF}$ and $2 \mathrm{modes}$, those are $2^{\text {nd }}(1 \mathrm{st}$ symmetrical heaving mode) and $12^{\text {th }}\left(1^{\text {st }}\right.$ symmetrical torsional $)$ modes SBS analysis $(\alpha=0$ degree $)$ changes to $94 \mathrm{~m} / \mathrm{s}$ obtained by multi-modes SBS analysis taking into account of 6 major mode, those are $1^{\text {st }(1 \mathrm{st}}$ symmetrical lateral mode $), 2^{\text {nd }}, 10^{\text {th }}\left(2^{\text {nd }}\right.$ symmetrical lateral mode $), 11^{\text {th }}$ ( $2^{\text {nd }}$ symmetrical heaving mode), $12^{\text {th }}$ and $13^{\text {th }}$ ( $3^{\text {rd }}$ symmetrical heaving mode) modes, because of stabilization effect by other modes.

In order to evaluate the effect of multi-modes on flutter instability from 2DOF case of certain virtual cable-stayed bridges with different span length from $500 \mathrm{~m}$ to $1500 \mathrm{~m}$, and suspension bridges with from $500 \mathrm{~m}$ to $4000 \mathrm{~m}$. Vibrational heaving and torsional modes of these with certain flat steel box girder are obtained dynamic structural analysis are analyzed up to $50^{\text {th }}$ modes. The aerodynamic derivatives are used Theodorsen function. As the results on Vcr obtained by multi-modes(2DOF) SBS analysis and 2modes (2DOF), drastic difference is not observed, but it should be noted that multi-modes analysis does not always larger Vcr than 2 mode analysis. Basing these analysis, the difference of Vcr obtained by multimodes analysis and 2 modes analysis is up to approximately $10 \%$.

\section{Selberg Formula}

Selberg formula[18] has been widely used for estimation of flutter critical velocity, in primary stage of design of long span bridge, as a desk work. Vcr obtained from Selberg Formula is for thin plate section, so the exact Vcr should be investigated by wind tunnel tests using scaled section-model or full scale elastic model, in indirect, measurement of aerodynamic derivatives or direct measurement of Vcr. However, how to be driven this useful Selberg Formula has been not clarified. Under following simple assumptions, significantly similar formula can be obtained as follows(Matsumoto and et al.[15]).

Assumptions:1. When torsional frequency, $\mathrm{f}_{\varphi}$, decreasing with wind velocity, is identical to heaving frequency, $\mathrm{f}_{\eta}$, no-affected by wind velocity, that is $\mathrm{f}_{\eta}=\mathrm{f}_{\eta 0}$, flutter appears.

1. $\mathrm{f} \varphi$ is characterized by only $A_{3} *$, and $A_{3} *$ is expressed by $A_{3} *=((\pi / k)(F(k) / k-G(k) / 2))^{1 / 2}$.

2. f $\eta$ is characterized by $\mathrm{H}_{4} * \mathrm{f}_{\eta}=\left(\mathrm{f}_{\eta 0}{ }^{2}-\rho \mathrm{V}^{2} \mathrm{kH}_{4} * /\left(4 \pi^{2} \mathrm{~m}\right)\right)^{1 / 2}, \mathrm{H}_{4} *=-(2 \pi / \mathrm{k}) \mathrm{G}(\mathrm{k})$

3.Using quasi-steady assumption,: $\mathrm{F}(\mathrm{k})=1$ and $\mathrm{G}(\mathrm{k})=0$, where $\mathrm{k}$ is reduced velocity $=\mathrm{b} \omega / \mathrm{V}$. 
Then Vcr can be expressed similarly with Selberg Formula as follows:

$\operatorname{Vcr}=3.71 f_{\varphi 0}(2 b)\left((m I)^{1 / 2} /\left(\rho(2 b)^{3}\right)\left(1-\left(f_{\varphi 0} / f_{\eta 0}\right)^{2}\right)\right)^{1 / 2}$

$\mathrm{Vcr}=3.81 \mathrm{f} \varphi 0(2 \mathrm{~b})\left((\mathrm{mI})^{1 / 2} /\left(\rho(2 \mathrm{~b})^{3}\right)\left(1-\left(\mathrm{f}_{\varphi 0} / \mathrm{f}_{\eta 0}\right)^{2}\right)\right)^{1 / 2}$ tangular section
(7) : Selberg Formula

(8) : obtained from upper assumptions for thin rec-

The Vcr-values calculated two formulas under some structural dynamics and exact ones analyzed by CEV analysis and SBS analysis are compared in Fig. 10. It is verified that both results on Vcr obtained by equation(7) and equation(8) are significantly close.

\section{Lesson from wind tunnel tests of full scale ealastic model of Akashi KailyoBridge}

A series of wind tunnel tests have been carried out by Honshu-Shikoku Expressway Co. Ltd.(at present) to clarify its fundamental aerostatic and aerodynamic characteristics. A full scale elasitic model test have been carried out to verify its flutter instability property by use of 1/100 scaled model. Its flutter instability obtained by wind tunnel test is compared with varoius flutter analyses as shown in Fig.11. There are some difference in $\mathrm{V}-\delta$ diagram, but some import informations on flutter analysis could be obtained.

1. Conventional 2DOF and 2modes flutter analysis gives us significant different Vcr from Vcr obtained by wind tunnel test.

2. Remarkable decreasing property of damping at certain high wind velocity obserbed by wind tunnel test can be reproduced by $3 \mathrm{DOF}$ and multimodes flutter analysis.

3. Taking into account of particular structural dynamics of 12 th mode, that is $1^{\text {st }}$ symmetrical torsional mode, accompanies with significant lateral displacement (see Fig.12) and effect of this structural coupling between torsion and laetral displacement, 2DOF flutter analysis camn give significntly similar with flutter characterisctics obtained by 3DOF multi-modes flutter analysis. (Matsumotoand et al. [15]).

4. Basing on the results of study on flutter instability of Akashi Kaikyo Bridge, for precise evaluation of flutter instability of long span bridge 3DOF and multi-modes flutter analysis might be definitely required.

\section{Flutter stabilization of long span bridges}

Describing at $\mathrm{xx}$ role of faerodynamic derivatives, $\mathrm{TB}$ and $\mathrm{HB}$ coupled flutter are mainly excited by $\mathrm{A}_{2} *$, $\mathrm{A}_{1} *$ and $\mathrm{H}_{3} *$, and $\mathrm{H}_{1} *, \mathrm{~A}_{1} *$ and $\mathrm{H}_{3} *$, repectively. Therefore, reduction of absolute values of $\mathrm{A}_{1} *$ and $\mathrm{H}_{3} *$ is definitely requried.

Taking into account of the equivalent aerodynamic derivatives of proto type bridge can be expressed by vibrational mode and aerodynamic derivatives characterized by geometrical shape of girder at cordinate $\mathrm{x}$.

For example, regarding $\mathrm{A}_{1}{ }_{\text {eq }}$ (see equation(9)), if bridge girders along bridge axis with $\mathrm{A}_{1} *>0$ and $\mathrm{A}_{1} *<0$ would be successfully combined by for example grating girder $\mathrm{B}$ (see Fig.13.1) and grating girder $4 \mathrm{~F}$ (see Fig 13.2) significant reduction of $\mathrm{A}_{1} *_{\text {eq }}$ can be satisfied.

$$
A_{1, e q}^{*}=\frac{\int \mu_{\eta i} \mu_{\phi j} A_{1}^{*} d x}{\int \mu_{\phi j}{ }^{2} d x}
$$


(9)

Suitable combination (see Fig.14.1) of these two different girders can realize complete stabilization against coupled flutter as shown in Fig.14.2.

\section{Application of Flutter-Generation of Propulsion Force}

\subsection{Generation of Propulsion Force}

According to former literatures, instantaneous propulsion force might be generated by coupling motion of heaving and pitching as term related to thin-airfoil theory, $F p_{\text {air-foil }}$, which consists in lift and drag force, $F p_{L \& D}$, and virtual mass effect, $F p_{\text {mass }}$, and jet disgorging term, $F p_{j e t}$. Then, the propulsion force, FP, can be expressed as follows:

Airfoil Theory term 1 :

$F p_{L \& D}=L\left(\alpha_{r e}\right) \sin \alpha_{r e}{ }^{*}-D\left(\alpha_{r e}\right) \cos \alpha_{r e}{ }^{*}$

$=(1 / 2) \rho V_{r e}^{2} 2 b l C_{L}\left(\alpha_{r e}\right) \sin \alpha_{r e}-(1 / 2) \rho V_{r e}{ }^{2} 2 b l C_{D}\left(\alpha_{r e}\right) \cos \alpha_{r e}{ }^{*}$

where, $L, D, C_{L}, C_{D}$ : unsteady force and coefficients

$V_{r e}=\left\{V^{2}+(d \eta / d t)^{2}\right\}^{1 / 2}$,

$(10.2)$

$\alpha_{r e}{ }^{*}=\arctan \{(d \eta / d t) / V\}$,

$\alpha_{r e}=\alpha_{r e \eta}{ }^{*}+\phi$

Airfoil Theory term 2 :(Virtual Mass Effect) (Karman\&Sears [19]):

$L_{\text {mass }}=\pi \rho b^{2} l\left(d \eta^{2} / d^{2} t+V d \phi / d t\right):$ normal to plate, at $\eta(t)=0$

$F p_{\text {mass }}=L_{\text {mass }} \sin \phi$ : propulsive component, at $t=0$

Jet Disgorging term:

$F p_{\text {jet }}=\rho A_{0}\left(V+v^{)}\left\{\left(V+v_{p}\right)-V\right\}=\rho \mathrm{A}_{0} \mathrm{v}_{\mathrm{p}}(\mathrm{V}+\mathrm{v})\right.$

where, $v_{\mathrm{p}}=\mathrm{v} / 2(10.8)$

$\mathrm{A}_{0}$ : effective area at near trailing edge where jet passes into wake:,

$v_{p}$ : disgorging jet velocity through $\mathrm{A}_{0}$

$v$ : jdisgorging jet velocity in a wake

Propulsion force in term of airfoil theory, $F p_{L \& D}$, and jet disgorging term, $F p_{j e t}$, show the maximum at having velocity maximum, that is pitching angle of zero in H-90 flutter mode, on the other hand $F p_{\text {mass }}$ shows the maximum at zero heaving velocity, that is maximum pitching displacement.

Propulsion force, FpL\&D, is classified into 6 cases depending combination of torsional and heaving displacement, as follows:

I.Up-ward heaving motion $\left(\alpha^{*} \mathrm{re}<0\right)$

I. 1 Positive torsional angle $(\varphi>0)$

I.1.1 Absolute value of Torsional angle is larger than the one of relative angle of attack due to heaving velocity: $|\varphi|>\mid \alpha^{*}$ re $\mid$ (case1)

I.1.2 Absolute value of Torsional angle is smaller than the one of relative angle of attack due to heaving velocity: $|\varphi|<\mid \alpha^{*}$ re $\mid$ (case2)

I. 2 Negative torsional angle $(\varphi<0) \quad($ case 3$)$ 
II .Down-ward heaving motion $\left(\alpha^{*}\right.$ re $\left.>0\right)$

II .1.Positive torsional angle $(\varphi>0) \quad$ (case4)

II .2 Negative torsional angle $(\varphi<0)$

II .2.1 Absolute value of Torsional angle is smaller than the one of relative angle of attack due to heaving velocity: $|\varphi|<\mid \alpha^{*}$ re $\mid$ (case5)

II .2.2 Absolute value of Torsional angle is larger than the one of relative angle of attack due to heaving velocity: $|\varphi|>\mid \alpha^{*}$ ren (case6).

These 6 cases and Lift and Drag induced by relative velocity are shown in Fig.29. As far as airfoil theory term 1explained before, from these generation mechanism of Lift and Drag depending torsional and heaving displacement, the following conditions to generate the positive propulsion force as a propulsive component of lift force, $F_{L \& D}$, should be essentially required:

$$
\left(\eta_{0} / \mathrm{b}\right) / \varphi_{0}>\mathrm{Vr}=\mathrm{V} / \mathrm{b} \omega
$$

For that the propulsive component of lift is larger than the breaking force caused by drag:

$\gamma\left(\alpha_{\mathrm{re}}\right) \tan \alpha_{\mathrm{re}}-1>0$

where,

$\eta_{0}$ and $\varphi_{0}$ : amplitude of heaving and torsional motion of flapping plate, respectively

$\mathrm{V}$ : propulsion velocity (or oncoming flow velocity)

$\omega$ : circular frequency of flapping plate

$\gamma\left(\alpha_{\text {re }}\right)$ : lift and drag ratio $\left(=\mathrm{L}\left(\alpha_{\mathrm{re}}\right) / \mathrm{D}\left(\alpha_{\mathrm{re}}\right)\right)$

$\alpha_{\mathrm{re}}$ : relative angle of attack $\left(=\alpha_{\mathrm{re}}{ }^{*}+\varphi\right)$

$\alpha_{\mathrm{re}}{ }^{*}$ : angle of attack induced by heaving velocity $(=\arctan (\mathrm{d} \eta / \mathrm{dt}) / \mathrm{V})$

Taking into account of 6 cases as shown in Fig.15, H-90 flutter mode, explained before, can generate at all moment positive propulsion force, $F_{\mathrm{L} \& D}$, if upper conditions formulas 11 and 12 are satisfied.

Previous studies on navigation mechanism of fish swimming(Tanaka and Nagai[8]) and ship navigation by flapping plates(Terada and et al., [9], Barannyk, Buckham and Oskai[10]) reported that the coupled motion on tail-fins of fish and flapping plate controlled by H-90 flutter mode can effectively generate propulsion force.

On the other hand, as far as propulsion force generated by jet disgorging effect, its generation mechanism, including $\mathrm{A}_{0}, \mathrm{v}_{\mathrm{a}}$ and $\mathrm{v}$ in equation (10.7) and equation(10.8), has not been verified at present. (Barannyk et al.[10]).

In Isogai's CFD result on flutter power generation by double thin airfoils obtained by jet disgorging for double airfoils in out-phase H-90 modes in terms, disgorging flow can be visualized (Isogai [20]).

Isogai and et al.[7] analyzed standing swimming of dolphin by CFD and verified dolphin could produce larger propulsion force than its dead-weight $(138 \mathrm{Kgw})$ by coupled motion in H-90 mode (with heaving and torsion are $\eta_{0} / b=5.03$ and $\varphi_{0}=58.9$ degree and frequency $f_{0}=$ fin motion is $4.94 \mathrm{~Hz}$ ) as an optimized case.. Jet flow with

Maximum propulsion force can be generated twice in one cycle heaving motion in $\mathrm{H}-90$ mode, corresponding maximum absolute value of heaving velocity. This twice frequency of propulsion force generated by flapping plate in H-90 mode can be observed in the test result by Barannyk[21] . 


\subsection{Ship navigation test by double flapping plates controlled inverse phase $\mathbf{H}-90$ modes}

Terada et.al [9] studied on navigation test of ship model with $0.5 \mathrm{~m}$ width , 3.5m length and $194 \mathrm{Kgw}$ with flapping plate with size of $0.2 \mathrm{mx} 0.3 \mathrm{~m}$. Frequency of flapping plate and navigated velocity were reported $\mathrm{V}=0.5 \mathrm{~m} / \mathrm{s}$ when $\mathrm{f}_{0}=0.8 \mathrm{~Hz}$ and $\mathrm{V}=0.8 \mathrm{~m} / \mathrm{s}$ when $\mathrm{f}_{0}=1.2 \mathrm{~Hz}$. It should be noted that optimizing motion of fin was in H-90 control. Author also carried out ship navigation test by use of ship model with flapping plate controlled by $\mathrm{H}-90$ mode in order to verify the generation mechanism of propulsion force as an application of flutter instability of thin plate. The propulsion force measurement has been conducted by use of ship model with $2.5 \mathrm{Kgf}$ in weight, $0.72 \mathrm{~m}$ in length, $0.33 \mathrm{~m}$ in width and $0.01 \mathrm{~m}$ in submerged depth, as shown in Fig. 16. Two rigid, flexible and half-flexible two flapping plates were installed at near trailing edge, and they were controlled in inverse phase in order to cancel the sway forces, mutually. Each flapping plate was controlled in H-90 mode, individually. The distance at each neutral position between two plates was $0.22 \mathrm{~m}$. The size of flapping plates were, $0.04 \mathrm{~m}$ (half chord length for rigid plate), $0.08 \mathrm{~m}$ (half chord length for flexible plate), $0.06 \mathrm{~m}$ (height for all plates). The thickness of plates were $1.5 \mathrm{~mm}$ (for rigid and flexible plate) and $2.0 \mathrm{~mm}$ (for elastic plate). The pitching axis was fixed at upstream-ward quarter-point for flexible plate-2 and at mid-chord point for the others. The frequency of flapping plate was mainly $4 \mathrm{~Hz}$ and flow velocity in water channel. The propulsion forces were measured in still water. The amplitude of heaving and pitching motion was fixed as $0.02 \mathrm{~m}$ and $19.5^{\circ}$, respectively. Besides, navigation velocity of ship model was measured in still water. The maximum navigation speed for flexible flapping plate was observed as over $0.55 \mathrm{~m} / \mathrm{s}$ in the case of $f_{0}=4.35 \mathrm{~Hz}$, and the one for rigid plate $0.45 \mathrm{~m} / \mathrm{s}$ at $f_{0}=4.35 \mathrm{~Hz}$ as well.

The amplitude ratio between heaving and pitching motion should be optimized to realize the critical relative angle of attack of airfoil/ thin plate to make drag-lift ratio maximum, therefore for optimization of ship navigation, this amplitude ratio should be controlled depending on ship navigation velocity. In this test, this matter was not be taken into account, but this subject should be investigated in a future.

\subsection{Propulsion Force induced Jet Disgorging, Fpjet、 basing on CFD Analysis by Isogai for Dolphin Standing Swimming}

Described before on uncertainties on evaluation of propulsion force generated by jet disgorging, $\mathrm{F}_{\text {pjet }}$, might be approximately estimated from CFD results for standing swimming of dolphin in still water analyzed by Isogai and et al.[7], under assumption of quasi-steady lift and drag forces. CFD result showed dolphin can generate upward propulsion force to cancel dolphin weight $(\mathrm{W}=138 \mathrm{Kgf})$ by flapping motion of tail fin $\left(b=0.072 \mathrm{~m}\right.$ at center, $\mathrm{l}=0.432 \mathrm{~m}$, tail fin area $=0.0377 \mathrm{~m}^{2}$, aspect ratio $=4.96$ ) with frequency of $4.07 \mathrm{~Hz}$. Amplitude of torsional and heaving motions are $58.9^{\circ}$ and $0.36 \mathrm{~m}$, respectively. The tail-fin motion is controlled in almost H-90 flutter mode, where phase is not $-90^{\circ}$ degree but $-75.8^{\circ}$. In this case, maximum propulsion force of $2750 \mathrm{~N}$ can be generated at the instant of heaving maximum velocity, $9.25 \mathrm{~m} / \mathrm{s}$.

It should be noted that jet disgorging velocity in a wake is $\mathrm{v}=5.4 \mathrm{~m} / \mathrm{s}$ in eq.(). Relative angle of attack, $\alpha \mathrm{re}=\mathrm{d} \eta / \mathrm{dt} / \mathrm{V}+\varphi=90-58.9^{\circ}=31.1^{\circ}, \mathrm{C}_{\mathrm{L}}\left(\alpha_{\mathrm{re}}\right)=1.0$ and $\mathrm{C}_{\mathrm{D}}\left(\alpha_{\mathrm{re}}\right)=0.8$, of which values are for 3DOF delta wing measured by Okamoto and Jinba[22]. Then, basing on quasi steady lift and drag forces, FPquasi, can be calculated as $1595.5 \mathrm{~N}$. Furthermore, if effective area, $\mathrm{A}_{0}$, where jet is passing, near trailing edge of 
tail-fin can be expressed by $\mathrm{A}_{0}=0.1555 \mathrm{~m}^{2}\left(=\eta_{0} \mathrm{xl}=0.36(\mathrm{~m}) \mathrm{x} 0.432 \mathrm{~m}\right)$, besides jet disgorging up-ward velocity component is approximately $3.82 \mathrm{~m} / \mathrm{s}$. Then from eq.(10.7), maximum propulsion force at the moment of maximum heaving velocity, $\mathrm{d} \eta /\left.\mathrm{dt}\right|_{\max }$, generated by jet disgorging into wake, $\mathrm{Fp}_{\mathrm{jet}}$, is obtained as $\mathrm{Fp}_{\mathrm{jet}}=1136 \mathrm{~N}$. Therefore, the total maximum propulsion force, $\left.\mathrm{Fp}\right|_{\max }$, at the moment of maximum heaving velocity is obtained as $2730.5 \mathrm{~N}$ by summation of $\left.\mathrm{Fp}_{\text {quai }}\right|_{\max }$ and $\left.\mathrm{Fp}_{\text {jet }}\right|_{\max }$ at heaving velocity maximum. This value is similar to the maximum propulsion force obtained by CFD (by Isogai et al.[7]). Of course, there are many simplified assumption in this calculation, so these agreement might be eventual one. However, contribution ratios of $\left.\mathrm{Fp}_{\text {airfoil }}\right|_{\max }\left(=\left.\mathrm{Fp} \mathrm{F}_{\mathrm{LD}}\right|_{\max }\right)$ and $\left.\mathrm{Fp}_{\mathrm{jet}}\right|_{\max }$ to total maximum propulsion force, $\left.\mathrm{Fp}\right|_{\max }$, in might be roughly evaluated from this result. That means $\left.\mathrm{Fp}_{\mathrm{jet}}\right|_{\max }$ and $\left.\mathrm{Fp}_{\text {airfoil }}\right|_{\max }$ contribute to total maximum propulsion force, $\left.\mathrm{Fp}\right|_{\max }$ by $42 \%$ and $58 \%$, respectively.

\subsection{Flutter Power Generation}

The "Flutter Power Generation(FPG)" has been proposed by Isogai in 2003[3]. This is a practical application of coupled flutter. If forced torsional vibration to the plate or airfoil, then significantly intensive heaving vibration can be excited because of appearance of natural coupled flutter in flutter fundamental H-90 mode in this system. The point of this FPG is that enough small power for forced torsional motion can generate a big power by intensive heaving vibration of plate/airfoil. Isogai pointed that giving power for forced torsion is less 1\% of obtaining power by heaving motion Abiru and Yoshitake[4]. Author also represented FPG system, and it was confirmed that forced torsional motion given by tiny motor can excite heaving motion with large amplitude.(Matsumoto et al.[5] )

It should be noted that FPG system uses coupled flutter in H-90 flutter mode generated naturally in the fluid. In Ship navigation system with flapping plate has significant advantage in saving power for driving coupled motion of the flapping plate with suitable amplitude ratio between heaving and pitching motion. The detail is described below.

\subsection{Advantage of Flapping plate System for Ship Navigation}

Navigation system by use of flapping plate controlled by H-90 mode is thought to be significant advantage to get more effectively propulsion force by supplement of external smaller energy. To get positive propulsion force in terms of $F p_{L \& D}$, or $F p_{\text {quasi }}$, the following condition should be satisfied.

$$
\eta_{0} / b / \phi_{0}>V r
$$

where $V r=V / b \omega_{0}$

As indicated in Fig. 7, the amplitude ratio of heaving and pitching motion of naturally excited coupled flutter in H-90 mode of thin plate/thin airfoil does not satisfy the condition of positive propulsion force as expressed by equation (13).

In order to generate the positive propulsion force by coupled torsional and heaving motion, equations (11) and (12) are definitely satisfied. Therefore naturally generated coupled flutter of plate-like sections cannot generate positive propulsion force, because in amplitude ratio between heaving and torsional motion, $\eta_{0} / \varphi_{0}$ v.s. velocity diagram, equation(13) is not satisfied as shown in Fig.17. In another words, natural coupled flutter must generate negative propulsion force, which means generation downstream-ward force fluctuation during coupling motion in natural coupled flutter.

By the way, for ship navigation by the flapping plate, when ship starts from still state, initial power to generate the coupled motion, which satisfied equations (11) and equation(12), then ship moves with certain velocity, $\mathrm{V}$. At this moment in getting velocity $\mathrm{V}$, given torsional motion can generate heaving mo- 
tion by the mechanism of Flutter Power Generation (FPG), therefore, to get continuously the positive propulsion force to navigate a ship, the lack heaving amplitude, $\eta$ lack, should be added to satisfied equations (13) and (14). Namely in ship navigation with flapping plate, once ship starts, rather mount power would be saved aided by the mechanism of flutter power generation as illustrated in Fig. 38 .

However, a lot of further studies for needed for practical realization of ship navigation with flapping plate, however there must be significant advantage in ship navigation with flapping plate from the point of power saving.

\section{Conclusion}

2DOF with two modes, 3DOF with three modes and 3DOF with multi-modes flutter characteristics obtained by CEV (Complex Eigen Value )analysis and SBS(Step-by Step) flutter analysis show completely identical values in terms of damping $\delta$, frequency $\mathrm{f}_{\mathrm{F}}$, phase difference $\psi$ and amplitude ratio $\eta_{0} / \varphi_{0}$, exceptionally clarification of flutter branch. In 2DOF coupled flutter, T0 (Torsional branch with phase angle of 0 degree)mode and H-90(Heaving branch with phase angle of -90 degree) can characterize its flutter mode. By clarification on the role of aerodynamic derivatives on flutter instability, long spanned bridge with hybrid bridge girders along bridge axis with $\left(\mathrm{A}_{1} *>0, \mathrm{~A}_{2} *<0\right)$ and $\left(\mathrm{A}_{1} *<0, \mathrm{~A}_{2} *>0\right)$, respectively can completely stabile against flutter instability. By use of simple assumption, similar Vcr formula of thin plate with Selberg formula can be driven. Propulsion force is proposed to be composed by three factors, those are quasi-steady one, and related one to jet flow disgorging in to wake, those of which are maximum at crossing neutral position of heaving motion, and one related to virtual mass, which is maximum at maximum heaving acceleration following former literature. It is verified through ship navigation test with double flapping plates controlled in $\mathrm{H}-90$ mode that the intensive quasi-steady propulsion force and propulsion force generated by jet flow disgorging in to wake as unsteady effect at the moment of the maximum heaving velocity, $|d \eta / d t|_{\max }$, in $\mathrm{H}-90$ mode. This property is also confirmed by propulsion force measurement by flapping plate carried out by Barannyk et al.[10]. Furthermore, important role of H-90 mode for generation of propulsion force coincides with study by Terada et al. and pointing by Tanaka and Nagai[8]. Utilization of two flapping plates, controlled by inverse-phase H-90 mode, would generate effectively more intensive instantaneous propulsion force caused by intensive jet flow disgorging flow into wake. The ratio in total propulsion force of quasi-steady component and related jet flow one seems to depend on single or double flapping plate(s), its geometry, their distance between two flapping plates, their motion-property such as heaving and pitching amplitude and its ratio, phase-difference, frequency, and so on, but it can be roughly evaluated that they are some order contribution to total maximum propulsion force. Ship navigation with flapping plate controlled by H-90 would have great advantage to get effectively propulsion force with less power, because of utilization of Flutter power system. However, this study on propulsion force using flutter H-90 mode is on primary stage, therefore more studies should be needed including unsteady fluid dynamic force, jet disgorging property, efficiency of flapping plate system, realistic application of proto-type ship/boat and comparison of navigation efficiency with conventional screw propelling system.

\section{Acknowledgement}

The author would like to acknowledge to Mr. Kazumasa Okubo (Kajima Co. Ltd, Japan), Kazuaki Ito(Shimizu Co Ltd) and Hisato Matsumiya(Central Research Institute of Electric Power Industry, Japan) for their contribution to study on flutter, and Prof Noriaki Ishii, Mr. Shunnsuke Kometani (former graduate student) and Mr.TakumaTsuji (graduate student) Osaka Electro-Communication University (OTCU) for their contribution on ship navigation test. Furthermore, the author would like to acknowledge 
to Dr. Kouji Isogai of Professor Emeritus of Kyushu University, Japan, and Dr. Oleksandr Barannyk and Professor Peter Oshkai of University of Victoria, Canada, for exchanging information with various data through personal communications on propulsion force in relation to flutter, and Professor Wuyou Xu of Dalian University of Technology, China for personal communication of flutter instability of Sutong Bridge.

\section{References}

1. M.Matsumoto, H.Matsumiya, S.Fujiwara, and Y.Ito(2010)," New consideration on flutter properties based on step-by-step analysis", J. of WEIA, Vol.98, pp429-437

2. S.Kusuhara and M.Matsumoto(2010), "Horizontal Response of Full Elastic Model of Akashi-Strait Bridge at Flutter Onset", Proc. of WES10, Bristol, UK

3. Isogai, K., Yamazaki, M., Matsubara, M., and Asaoka, T.(2003), "Design study of elastically supported flapping wing power generator", Proc. of International Forum on Aero-elasticity and Structural Dynamics,

4. H.Abiru and A. Yoshitake (2010)," Flapping Wing Hydroelectric Power Generation System", Proc. of Advanced in Interaction and Multi-scale Mechanics(AIMM'10), Jeju, Korea

5. M.Matsumoto, K., K. Okubo and Y.Ito(2006),'Fundamental Study on the Efficiency of Power Generation by Use of the Flutter Instability", Proceedings of PVP 2006-ICPVT-11, 2006 ASME Pressure Vessels and Piping Division Conference, Vancouver, Canada

6. S.Aoki(2010)," Dynamic Simulation of the Wing Stroke Mechanism", Proc. of Advanced in Interaction and Multi-scale Mechanics(AIMM'10), Jeju, Korea

7. K.Isogai, G.Kariyazaki, M.Matsubara, M.Yamazaki,(2007) “ Propulsive Performance of Tail Fin of Dolphin-Approval by optimum design and Experiments-“ Proc. of Conference on Fluid Dynamics, pp293-296 (in Japanese)

8. I.Tanaka and M.Nagai, (1996), "Fluid Mechanics on Resistance and Propulsion-Learning from High Speed Swimming Capability of Fishes", Ship and Ocean Foundation,(in Japanese)

9. I.Terada, I.Yamamoto, T.Nagamatsu and Y.Imaizumi(1998),'Development of Oscillating Fin Propulsion System and Its Application", Technical Report of Mitsubishi Heavy Industry, Vol.35, No.2, (in Japanese)

10. O.Barannyk, B.Buckham and P.Oshkai (2010), "Effect of Chord-wise Flexibility and Depth of Submergence on an Oscillating Plate under Water Propulsion System", Proc. of the ASME $20103^{\text {rd }}$ Joint US-European Fluid Engineering Summer Seminar

11. M.Matsumoto and H. Ishizaki(2010), "Study on Propelling Forces by taking into account of Flutter Modes", Proc. of Advanced in Interaction and Multi-scale Mechanics(AIMM'10), Jeju, Korea

12. F.B. Farquharson, Aerodynamic Stability of Suspension Bridges, 1949, Part I-IV

13. Masaru Matsumoto, Hiromichi Shirato, Tomomi Yagi, Rikuma Shijo, Akitoshi Eguchi, Hitoshi Tamaki: Effects of aerodynamic interferences between heaving and torsional vibration of bridge decks: the case of Tacoma Narrows Bridge, Journal of Wind Engineering and Industrial Aerodynamics, Vol. 91, No.12-15, pp.1547-1557, December,

14. R.H.Scanlan and J.J.Tomko (1971),"Airfoil and Bridge Deck Flutter Derivatives”, J. of Eng. Mech. Division, 97, EM6, ASCE, pp1717-1737

15. M.Matsumoto, Flutter Instability of Structures, Proc.of the4th EAWCE (key note), Prague,,2005

16. F.Y.Xu and et.al., Aero-elastic divergences research of Sutong Bridge, Proc. of ICWE13, 2011

17. M.Matsumoto, H.Matsumiya, Study on Flutter characteristics of Akashi Kaikyo Bridge, 2009, Vol.65, No.65, pp 630-644 (in Japanese)

18. A. Selberg, Oscillation and aerodynamic Stability of Suspension Bridges, ACTA, Polytechnica Scannavica, Civil Engineering, Civil Engineering and Construction Series , 1961

19. T.V. Karman and W.R.Sears, (1938), "Airfoil Theory for Non-Uniform Motion", Journal of The Aeronautical Sciences, Vol.5, August, No.10, pp379-389

20. K.Isogai, personal communication

21. O.Barannyk, personal communication 


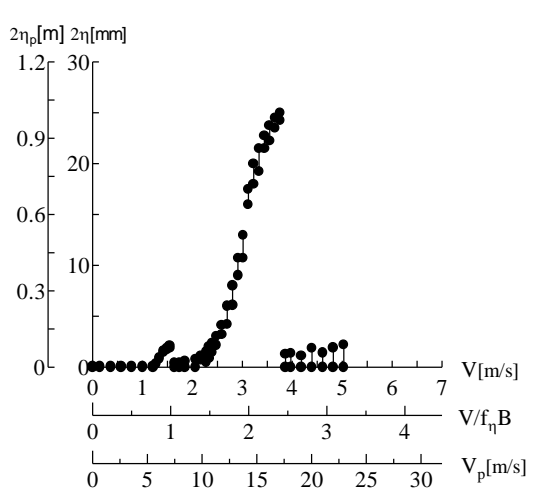

(a) Heaving

$1 \mathrm{DOF}$

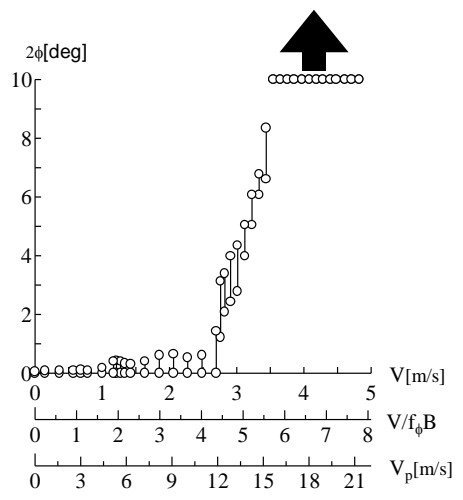

(b) Torsional

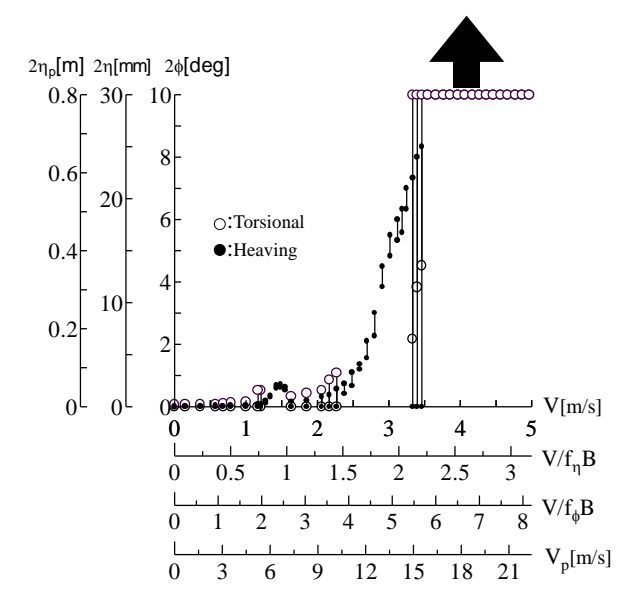

(c)Heaving and Torsional 2DOF

Fig.1 Torsional flutter and heaving vortex-induced vibration of Tacoma Narrows Bridge (Matsumoto and et al.[13]) ((a)f $\eta 0=5.28 \mathrm{~Hz}, \mathrm{~m}=2.524 \mathrm{~kg} / \mathrm{m}, \delta \eta 0=0.0206$,

$\mathrm{Sc} \eta=20.040)((\mathrm{b}) \mathrm{f} \varphi 0=2.05 \mathrm{~Hz}, \mathrm{I}=0.038 \mathrm{kgm}, \delta \varphi 0=0.174, \mathrm{Sc} \varphi=750.0)((\mathrm{c}) \mathrm{f} \varphi 0=2.05 \mathrm{~Hz}, \mathrm{f} \eta 0=5$ $.28 \mathrm{~Hz}, \mathrm{f} \eta 0 / \mathrm{f} \varphi 0=2.58, \delta \varphi 0=0.174, \mathrm{~m}=2.48 \mathrm{Kg} / \mathrm{m}, \mathrm{I}=0.038 \mathrm{Kgm}, \delta \varphi 0=0.174, \mathrm{Sc} \varphi=765.0$, $\delta \eta 0=0.0206, \mathrm{Sc} \eta=22.40)$ 

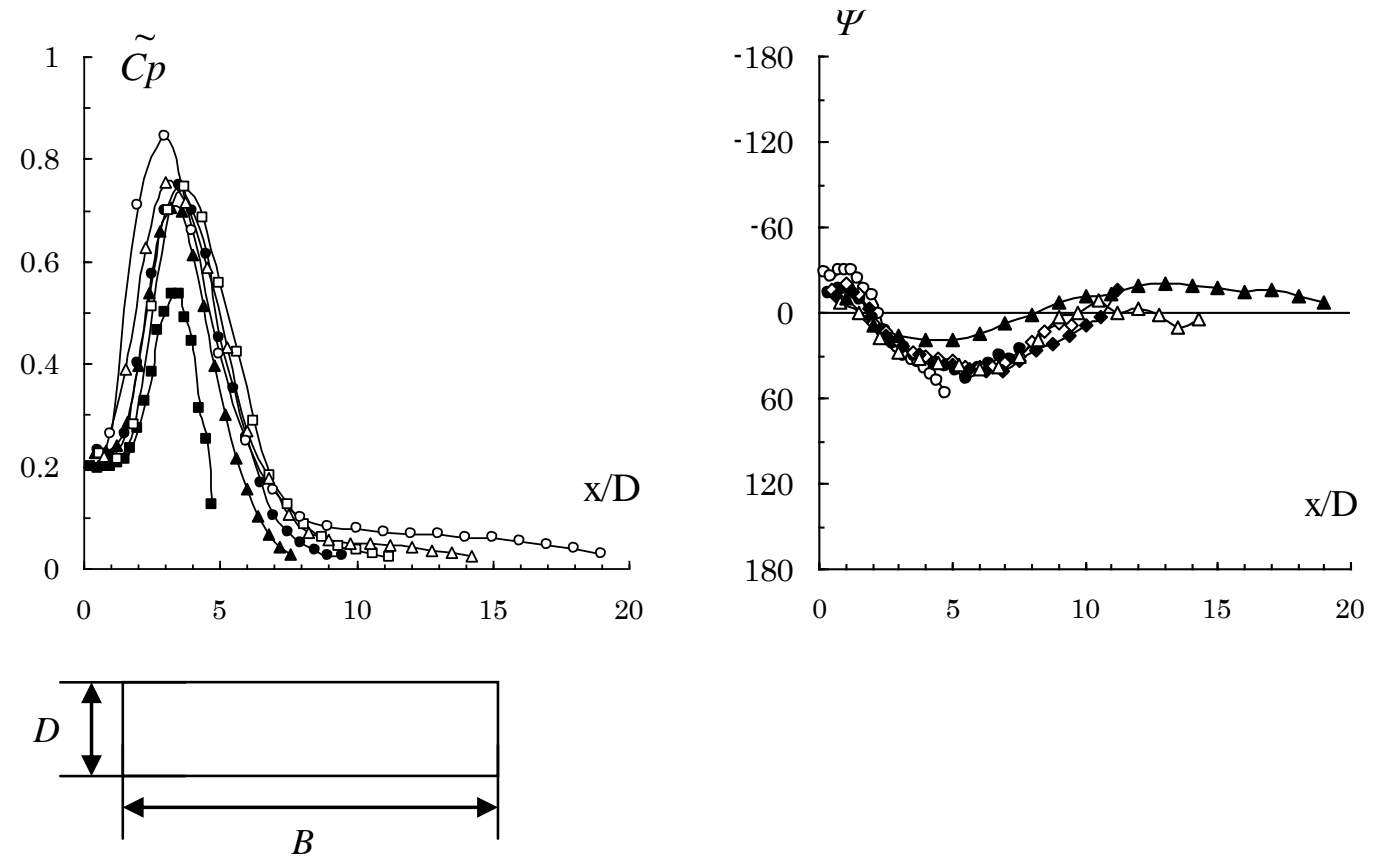

Fig.2 Similarity of unsteady pressure characteristics of rectangular cylinders with varoiu side ratios, $\mathrm{B} / \mathrm{D}=5,8,10,12.5,15$ and 20 , under forced torsional vibrastions (left: pressure amplitude synnchronized to forced torsional motion, $\mathrm{Cp}$, bottom right : phase of pressure to forced torsional motion, $\psi$ ) (Matsumoto[15]) 


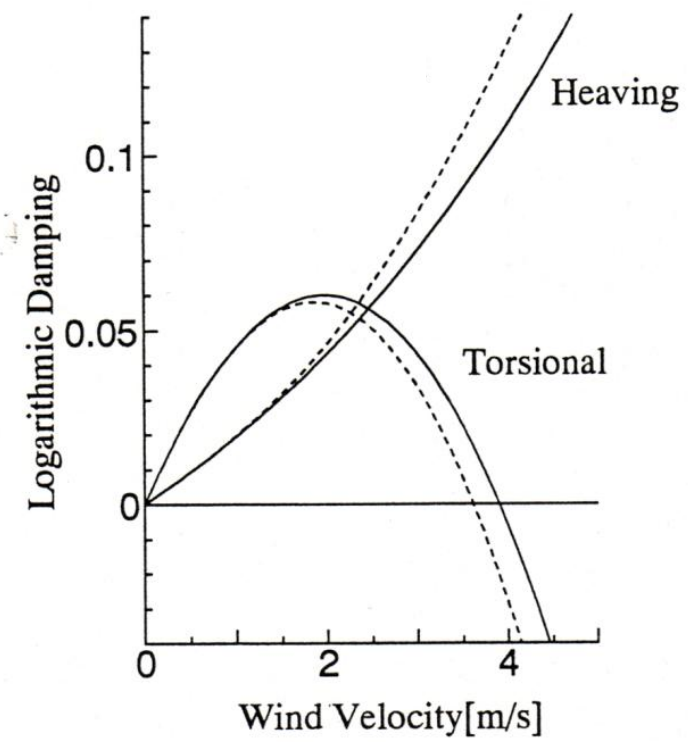

(a) rectangularcylinderwithB/D=5

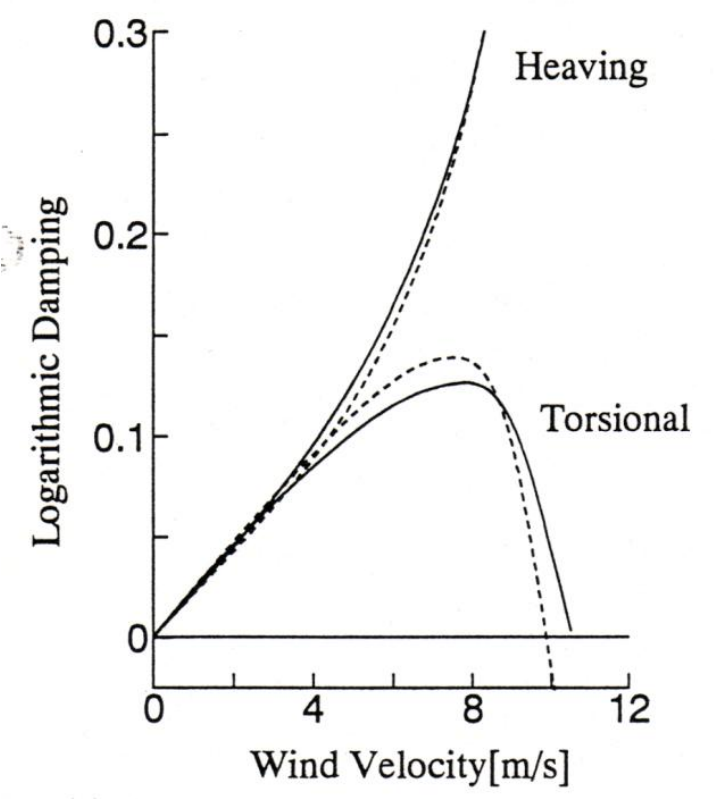

(b) rectangular cylinder with $\mathrm{B} / \mathrm{D}=20$

Fig.3 Vcr analogy by use of 2 aeroderivatives and 8 aerodynamic derivatives of rectangula cylinders with $\mathrm{B} / \mathrm{D}=5$ (left) and $\mathrm{B} / \mathrm{D}=20$ (right)( solid line: 8 derivatived used, dotted line: 2 derivatives, $\mathrm{A} 3 *$ and $\mathrm{H} 1 *$, used) (Matsumoto[15]) 


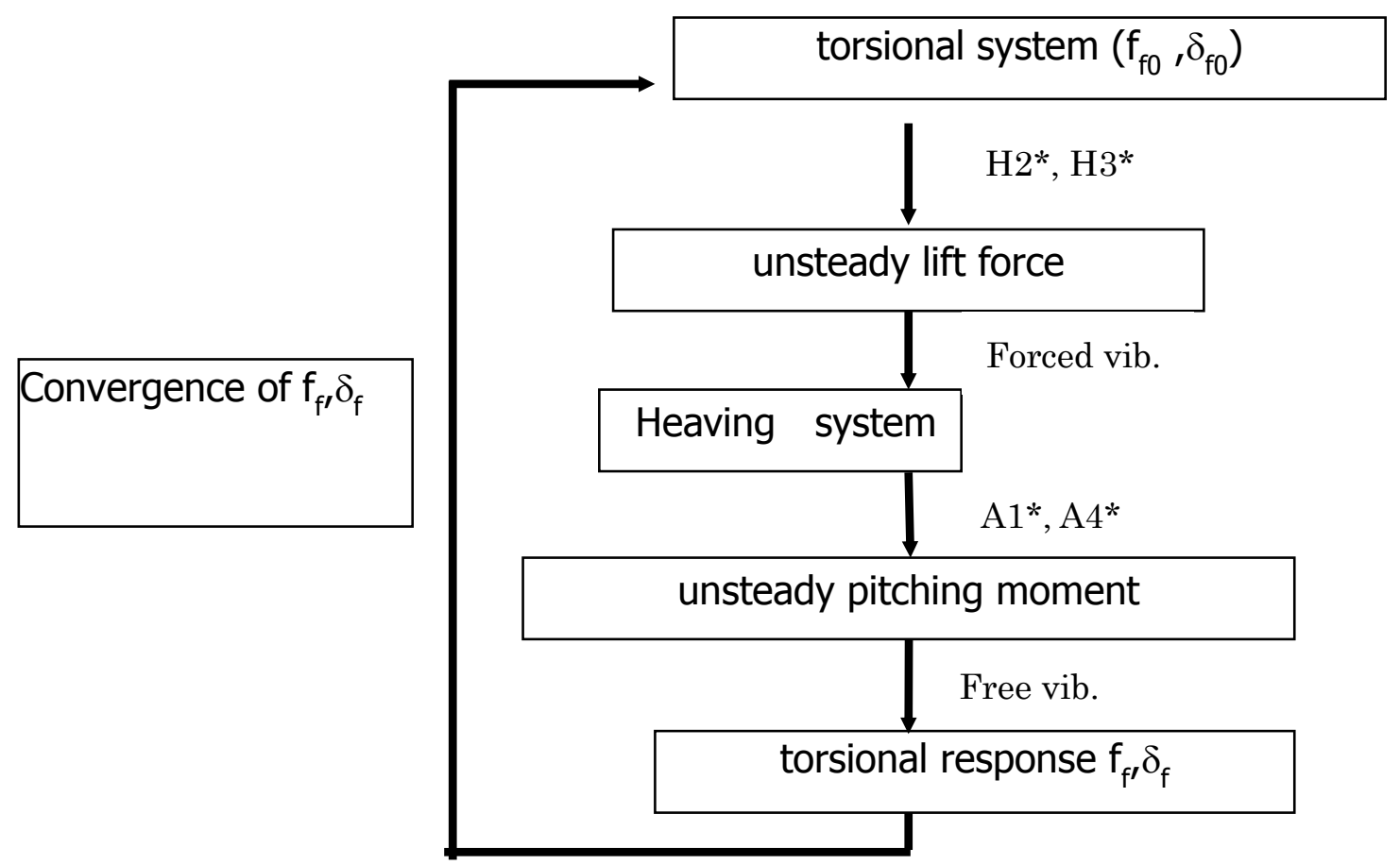

Fig.4 Flow chart 1 of SBS flutter analysis (For Torsional Branch) 


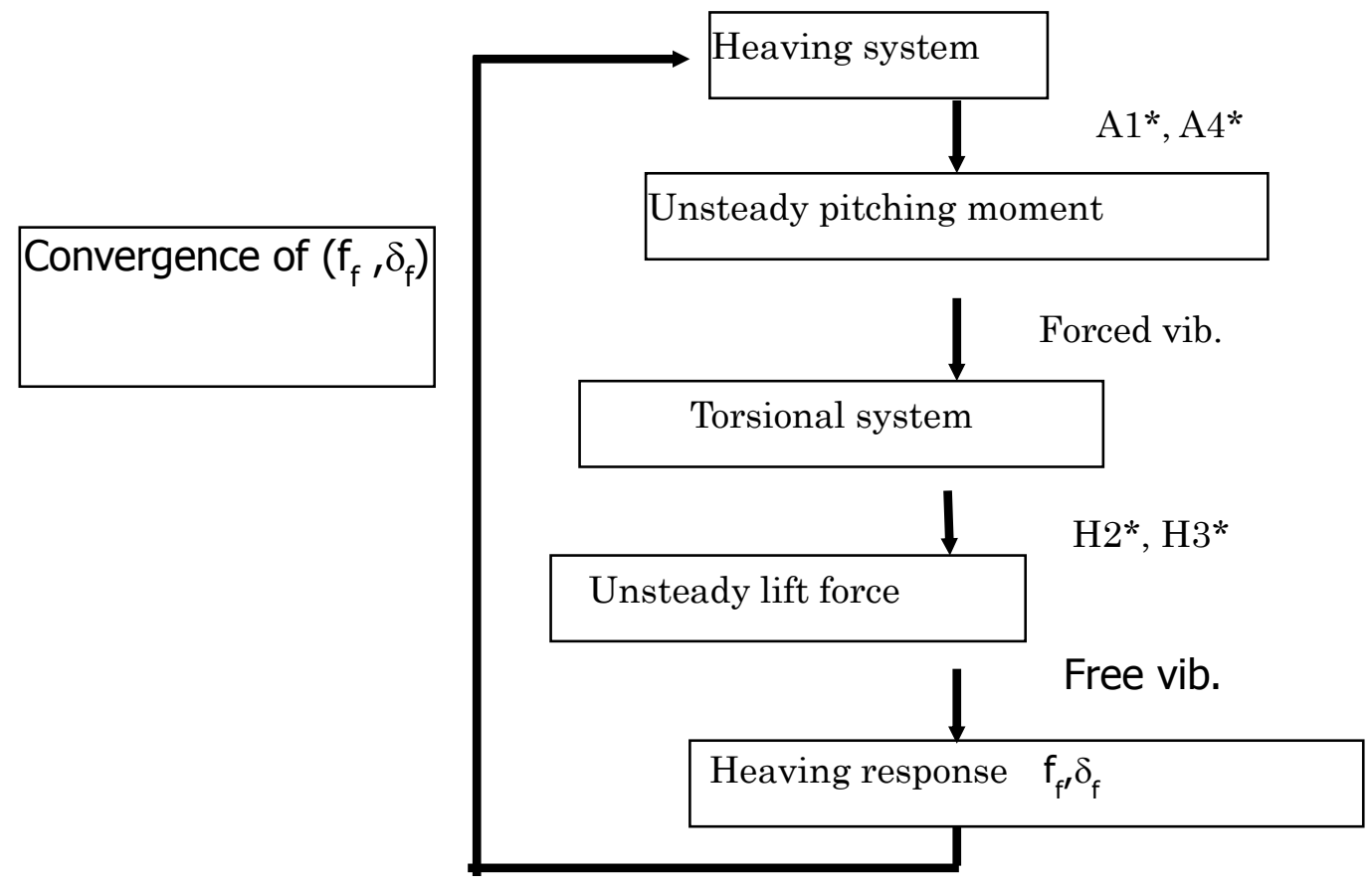

Fig.5 Flow chart 2 of SBS flutter analysis (for Heaving Branch) 


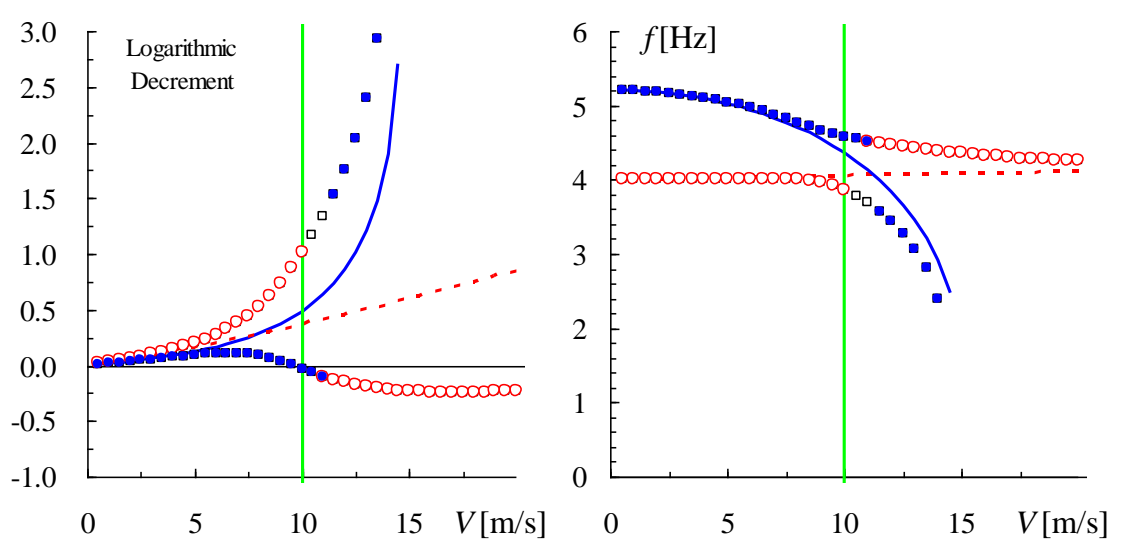

Fig.6 Damping, $\delta$, (left) and frequency, fF, (right) diagrams of thin plate analyzed by SBS analysis (red:heaving branch, blue:torsional branch, green line: flutter onset) $\mathrm{M}=2.42 \mathrm{Kg} / \mathrm{m}, \mathrm{I}=0.0181 \mathrm{Kgm} 2 / \mathrm{m}, \mathrm{B}=0.3 \mathrm{~m}, \mathrm{f}_{\eta}=4.0 \mathrm{Hx}, \mathrm{f}_{\varphi 0}=5.2 \mathrm{~Hz}$
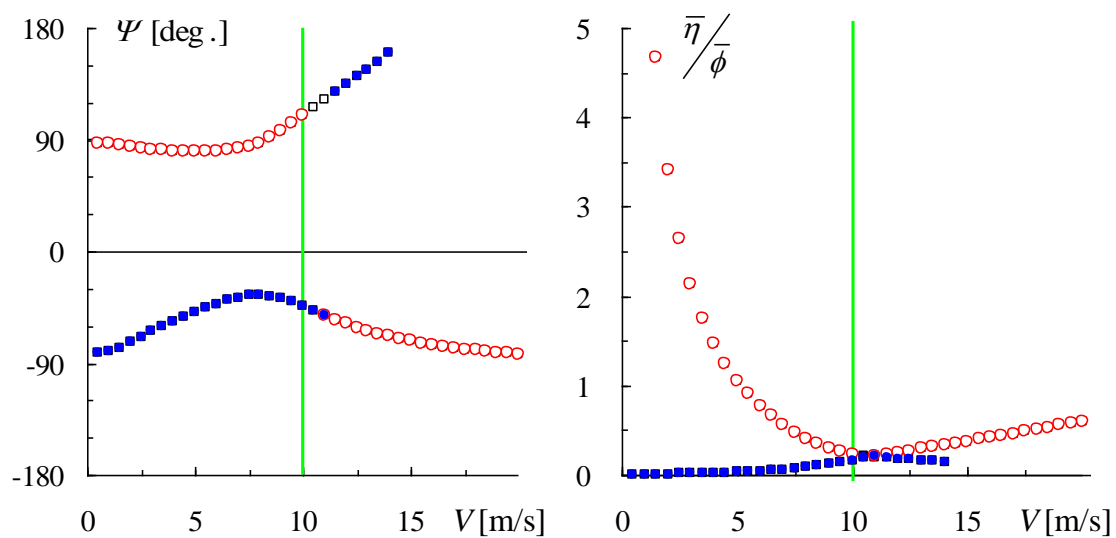

Fig.7 Phase(left), $\psi$, and amplitude ratio, $\eta_{0} / \varphi_{0}$, (right) diagrams of plate analyzed by SBS analysis

(red:heaving branch, blue:torsional branch, green line: flutter onset) $\mathrm{M}=2.42 \mathrm{Kg} / \mathrm{m}, \mathrm{I}=0.0181 \mathrm{Kgm} 2 / \mathrm{m}, \mathrm{B}=0.3 \mathrm{~m}, \mathrm{f}_{\eta}=4.0 \mathrm{Hx}, \mathrm{f}_{\varphi 0}=5.2 \mathrm{~Hz}$ 


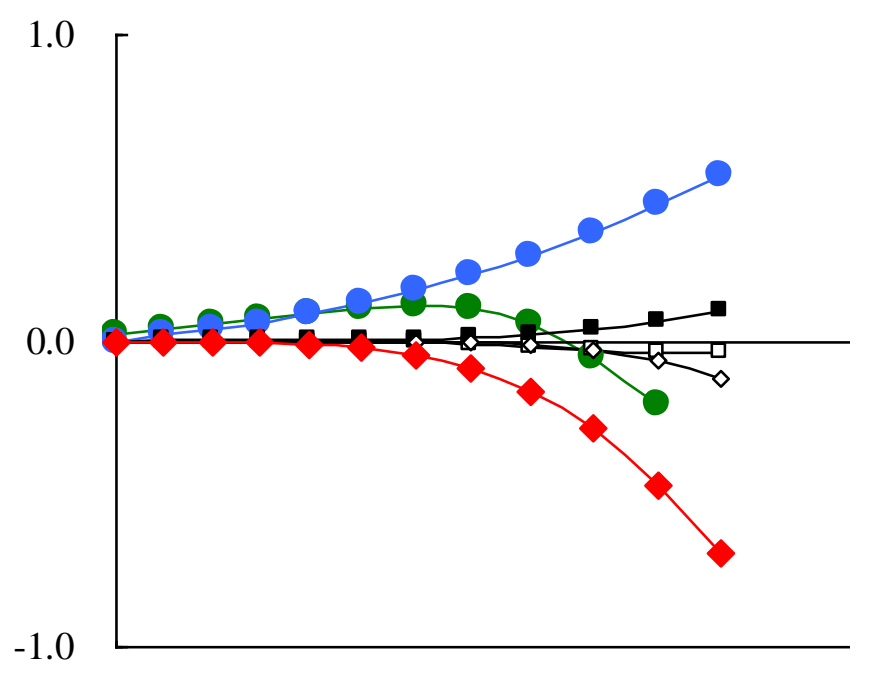

$$
\begin{aligned}
& : \delta_{F} \\
& :-\mathrm{a} A_{2}{ }^{*} \\
\square & :-\mathrm{ab} A_{1}{ }^{*}\left|H_{2}{ }^{*}\right| \cos \theta_{1} \\
\square & : \text { ab } A_{4}{ }^{*}\left|H_{2}{ }^{*}\right| \sin \theta_{1} \\
\nabla & :-\mathrm{ab} A_{1}{ }^{*}\left|H_{3}{ }^{*}\right| \cos \theta_{2} \\
\diamond & : \text { ab } A_{4}{ }^{*}\left|H_{3}{ }^{*}\right| \sin \theta_{2}
\end{aligned}
$$

(a) Torsional branch 


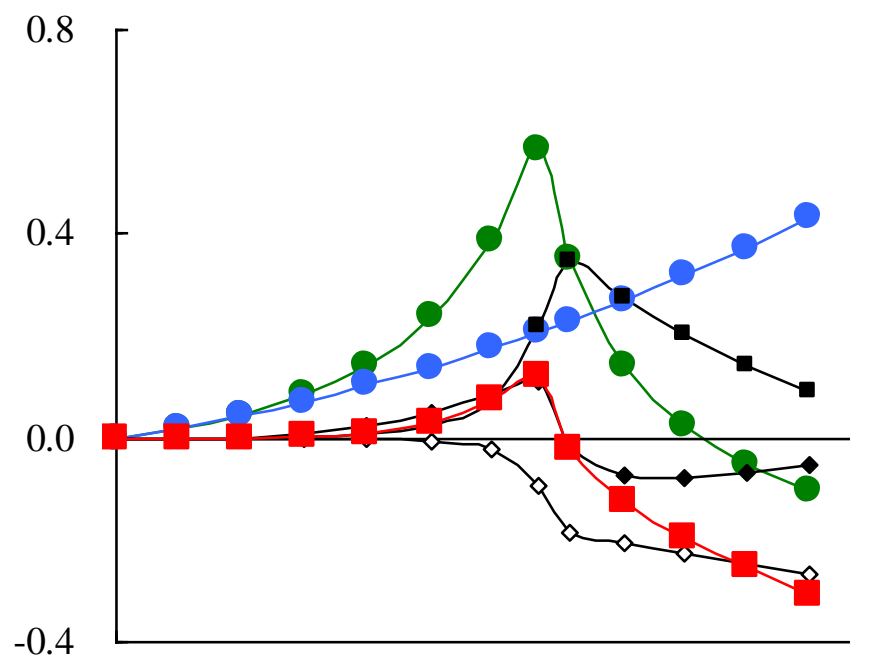

$$
\begin{aligned}
& : \delta_{F} \\
& :-\mathrm{a} H_{1}^{*} \\
& \mathbf{\square}:-\mathrm{ab}\left|A_{1}^{*}\right| H_{2}^{*} \cos \theta_{1} \\
& \square: \operatorname{ab}\left|A_{1}^{*}\right| H_{3}^{*} \sin \theta_{1} \\
& \diamond:-\mathrm{ab}\left|A_{4}{ }^{*}\right| H_{2}^{*} \cos \theta_{2} \\
& \diamond: \mathrm{ab}\left|A_{4}{ }^{*}\right| H_{3}^{*} \sin \theta_{2}
\end{aligned}
$$

(b) Heaving branch

Fig.8 Aerodynamic derivatives contribution to total damping $\delta$ of thin plate obtained by SBS analysis 

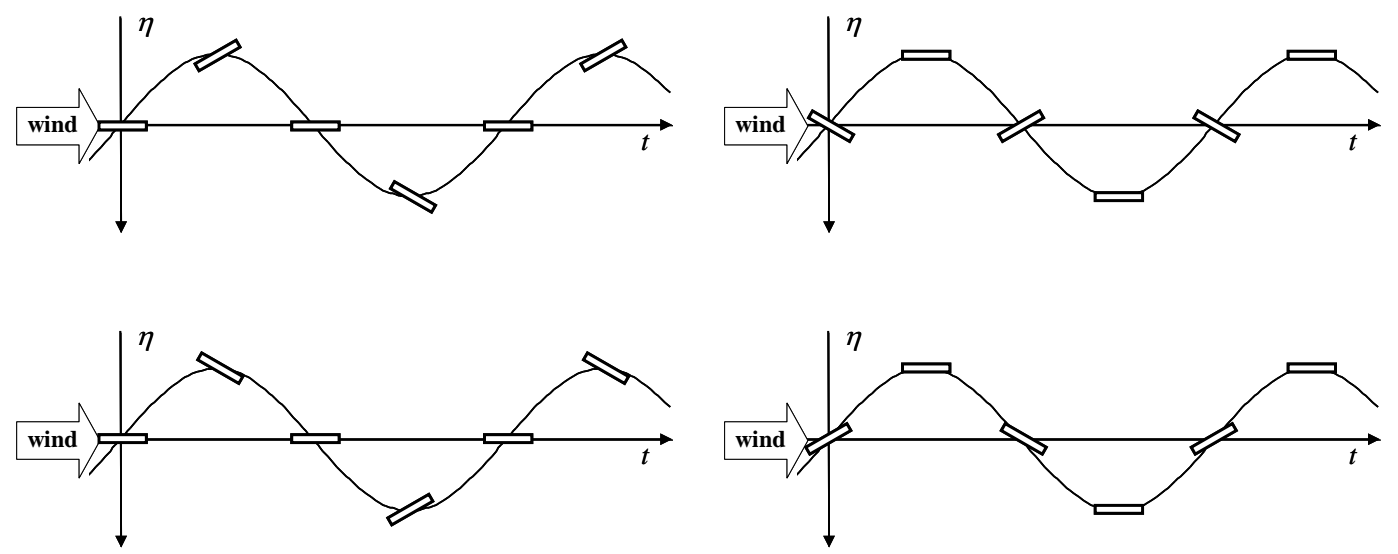

Fig.9 Flutter modes,: T0 (top-right)), T180(bottom-right), H-90(top-left) and H90(bottom-left) 


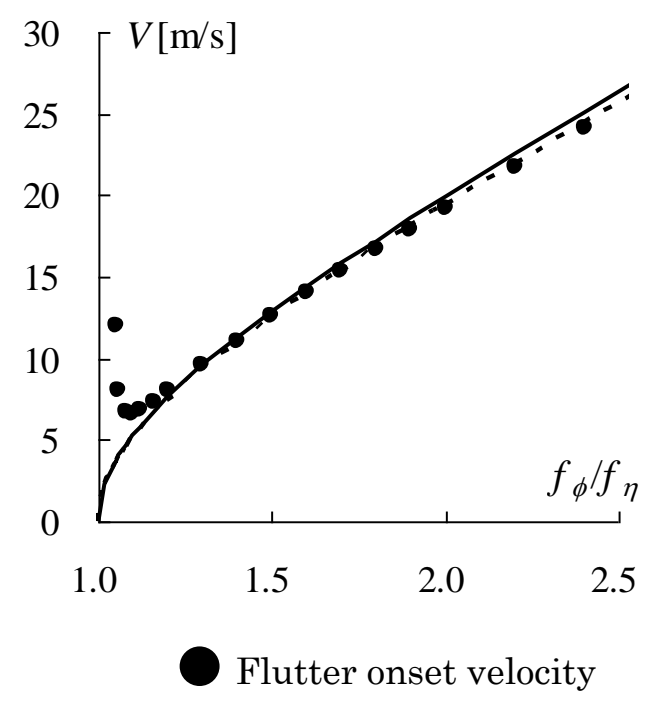

- Equation (8)

....... Equation(7) ( Selberg)

Fig.10 Comparison of Vcr of thin plate obtained by Selberg Formula(equation(7), Formula(equation (8) and Flutter Analysis (Matsumoto and et al. [15]) 

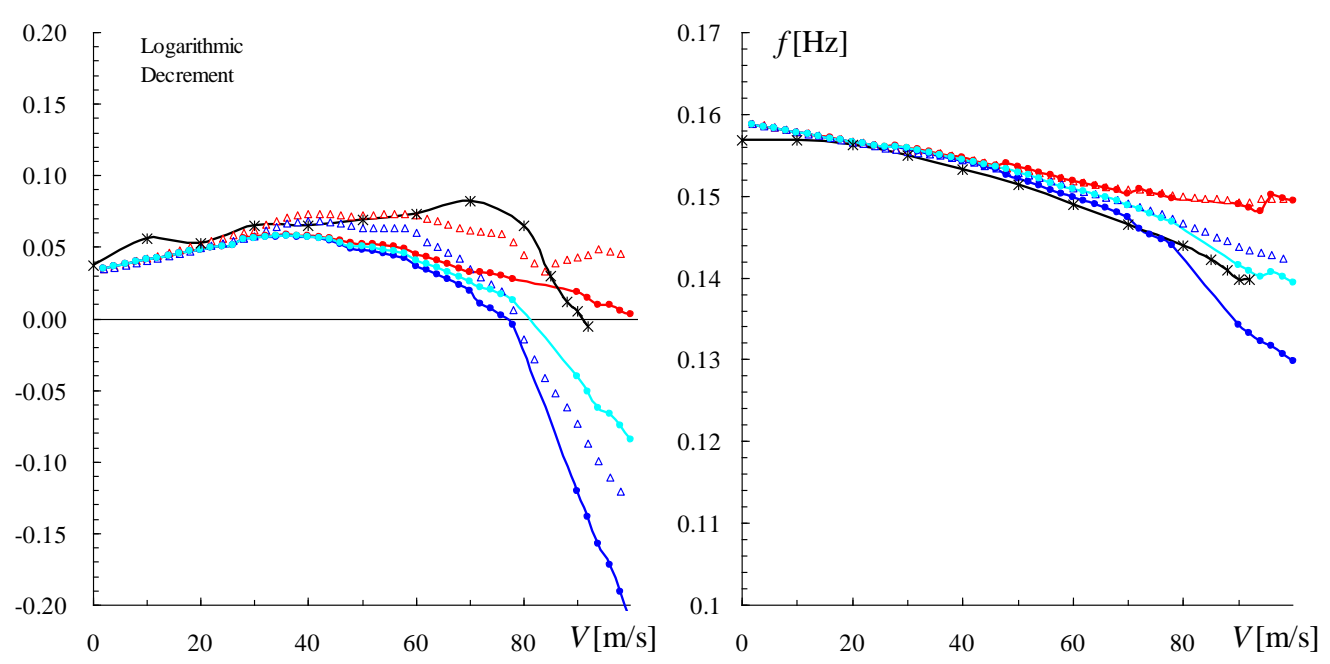

Fig.11 Comparison of flutter chatracteristics of Akasi Kaikyou Bridge, ontained by wind tunnel test and various flutter analyses (left: damping, right: frequency) (blue triangle: 3DOF and multi modes analysis, $\mathrm{x}$ and black solid line:experiment, light blue line and dark blue line: $2 \mathrm{DOF}$ analysis taking into accout of structural coupling of $12^{\text {th }}$ mode, red triangle: $2 \mathrm{DOF}$ and 2 modes analysis) 


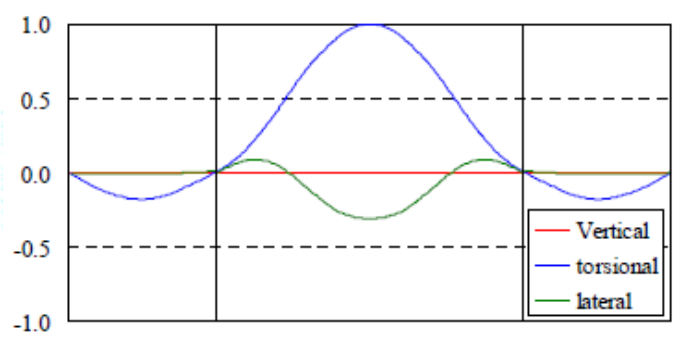

Fig,12 $12^{\text {th }}$ mode( $1^{\text {st }}$ symmetrical torsional mode $)$ accompanied with hlateral displacement (Akashi Bridge) 


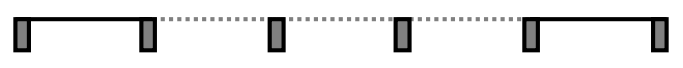

Fig.13.1 Grating girder of type $\mathrm{B} 0$ with $\mathrm{A}_{2} *>0$

and $\mathrm{A}_{1} *<0$

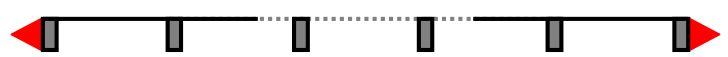

Fig.13.2 Grating girder of type $4 \mathrm{~F}$ with $\mathrm{A}_{2} *<0$ and $\mathrm{A}_{1} *>0$ 


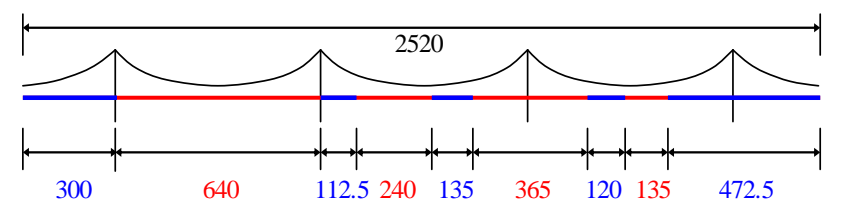

Fig.14.1 Hybrid girder combination along bridge axis ( red parts: type 4F girder,blue parts:type B0 girder )

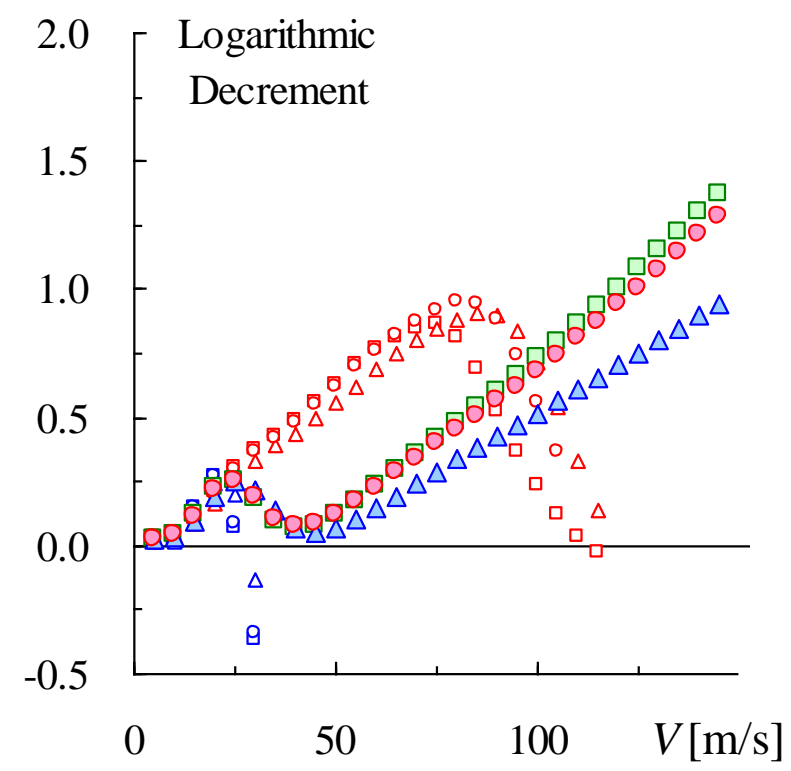

Fig.14.2 Damping property of suspension bridge with hibrid girders of type B0 and 4F (Full pink circle: summetrical mode of HB girders, full blue triangle: asymmetrical mode of HB girders, full green squre: asymmetrical mode at side span, red circle: asymmetrical mode of mono 4F girder, red triangle, red triangle : asymmetrical mode of mono $4 \mathrm{~F}$ gieder, red square: asymmetrical mode at side span of mono4F girde 


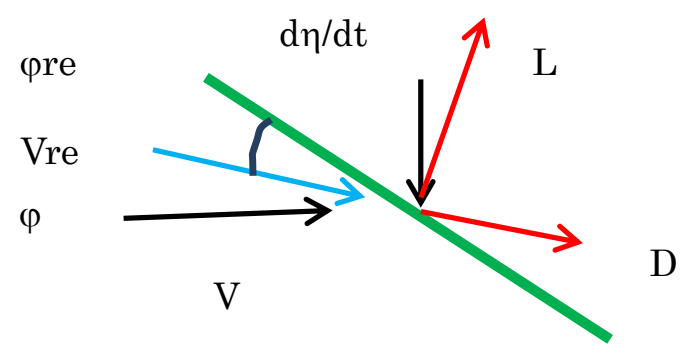

Case1

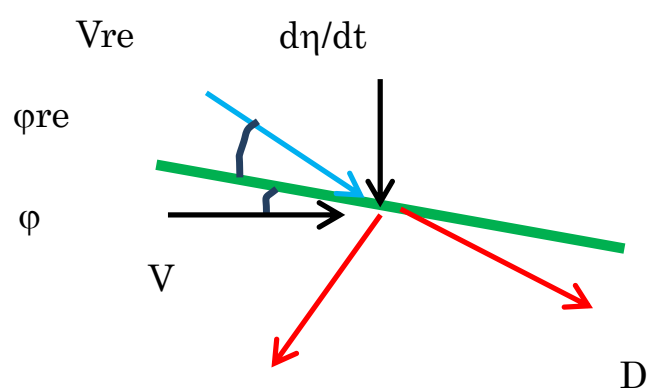

$\mathrm{L}$

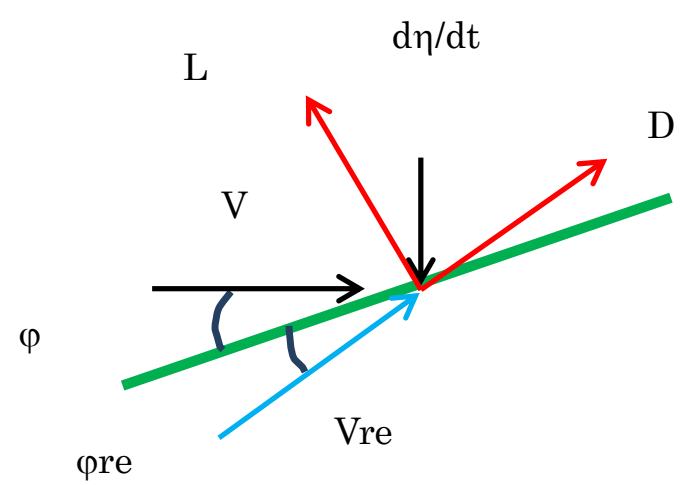

Case3 


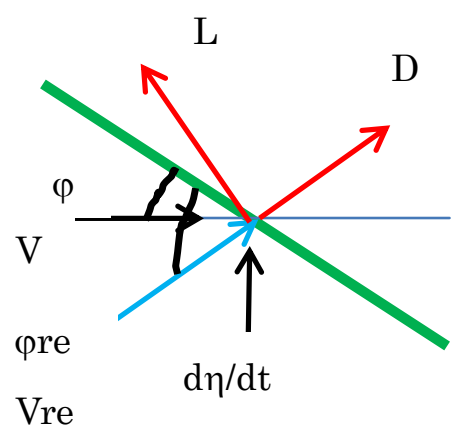

case 4

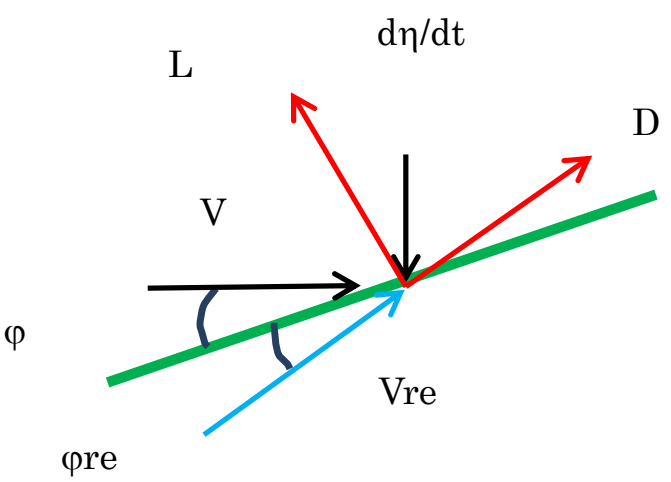

Case 5

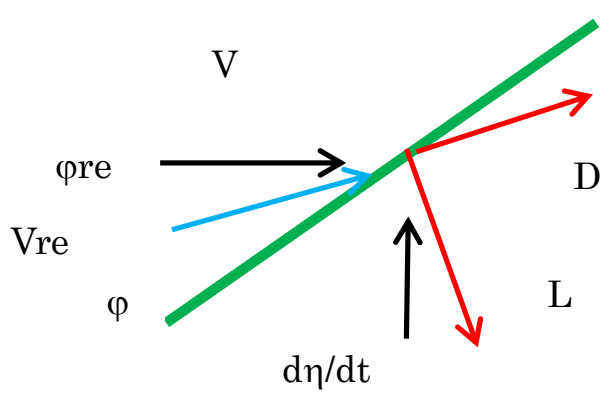

Case6

Fig.15 Lift and Drag Induced by Relative velocity Depending on Heaving and Torsional Displacement (green line : thin plate/ airfoil, light blue arrow: relative fluid velocity to airfoil, red arrows: lift and drag) 


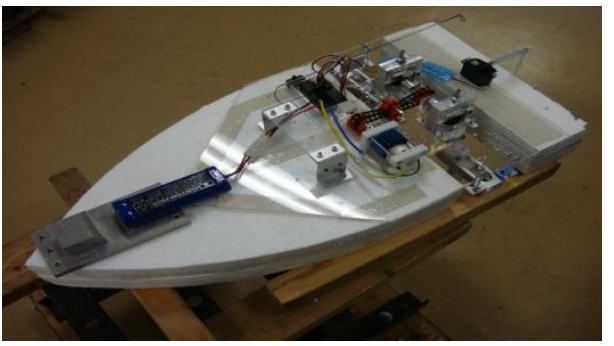

Fig.16 Ship model with double flapping plates 


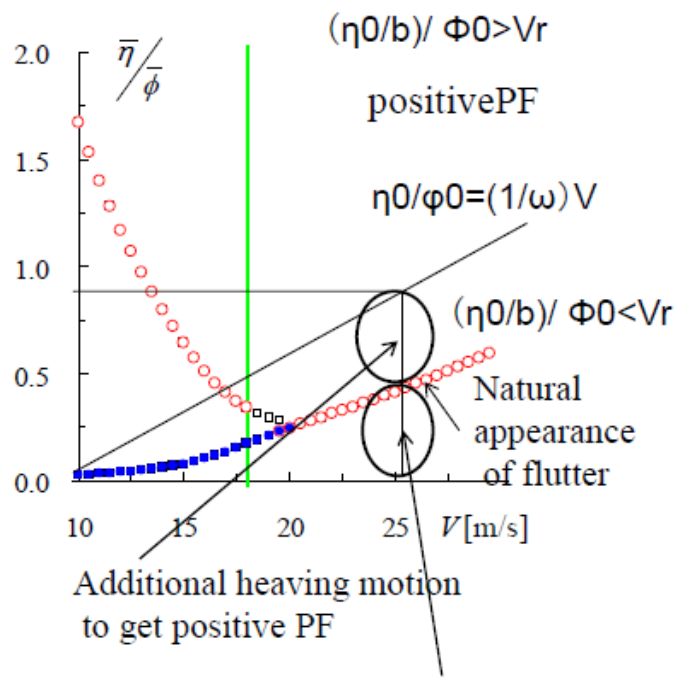

Heaving motion obtained by FPG

Fig.17 Flutter property, amplitude ratio, of thin plate and Propulsion force in flapping plate aided by FPG 